\title{
REVIEW
}

\section{The role and requirements of digestible dietary carbohydrates in infants and toddlers}

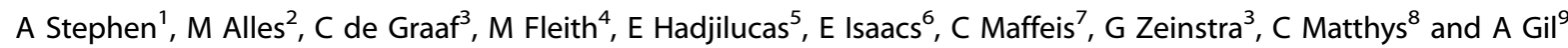

Digestible carbohydrates are one of the main sources of dietary energy in infancy and childhood and are essential for growth and development. The aim of this narrative review is to outline the intakes of digestible carbohydrates and their role in health and disease, including the development of food preferences, as well the consequences of excess carbohydrate. Key experts in these fields provided up-to-date reviews of the literature. A search of available information on dietary intakes of children below the age of 4 years was conducted from 1985 up to 2010. Articles and reports including information about sugars and/or starch intakes were selected. A number of factors limit the ability to obtain an overall picture of carbohydrate intakes and food sources in this age group. These include small numbers of intake studies, differing approaches to analysing carbohydrate, a variety of terms used to describe sugars intakes and a dearth of information about starch intakes. Data suggest that sweet taste is preferred in infancy and later food choices. There are few established adverse consequences of high intakes of digestible carbohydrate for young children. The greatest evidence is for dental caries, although this is influenced by high intake frequency and poor oral hygiene. Evidence for detrimental effects on nutrient dilution, obesity, diabetes or cognition is limited. In infants, minimum carbohydrate (mainly lactose) intake should be $40 \%$ of total energy, gradually increasing to $55 \%$ energy by the age of 2 years.

European Journal of Clinical Nutrition (2012) 66, 765-779; doi:10.1038/ejcn.2012.27; published online 4 April 2012

Keywords: young children; dietary carbohydrates; dietary intake; obesity; dental caries; cognition

\section{INTRODUCTION}

The early years of life are a period of very rapid growth. Appropriate nutrition is essential during this period: children who do not receive sufficient energy and nutrients will not sustain their expected growth and development. Digestible dietary carbohydrates, primarily lactose, are one of the main sources of dietary energy in this crucial period. Additionally, other key sources are starch and sugars.

This paper provides a narrative review of the role and suggested requirements for digestible carbohydrate in the diets of infants and toddlers. It provides an overview of current intakes where available worldwide and recommendations in Europe, describing the food sources, the weaning practices and geographical and age differences. In addition, it summarises how digestible carbohydrates are absorbed, their role in the development of food preferences and food choices and in cognition. Finally, the consequences of excess carbohydrate are reviewed, in each case by providing a summary of the available literature including, where available, the results of published systematic reviews of the issue.

\section{TERMINOLOGY}

Digestible dietary carbohydrates comprising two main categoriesstarch and sugars. Both the total and its two components suffer from problems of variability in definition and analysis, creating challenges when examining intakes and impacts on health. In infant formula and toddlers milk, maltodextrins are also commonly used and may be an important dietary component for infants and young children. However, these are rarely reported in dietary surveys.

\section{Carbohydrate}

There are two main ways in which the carbohydrate content of foods is determined, either by analysing carbohydrate components directly and adding these together, or by calculating carbohydrate content 'by difference'. ' A detailed description of those two methodologies can be found in Supplementary Appendix 1, the advantages and disadvantages of the different methods are described as well.

\section{Sugars}

There are a large number of terms used to describe sugars and their components, such as sugar(s), total sugars, total available sugars, free sugars, added sugars, refined sugar(s), simple sugars, discretionary sugar, intrinsic sugars, extrinsic sugars, non-milk extrinsic sugars (NMES) and caloric sweeteners. ${ }^{2-10}$ The existence of these many different terms and their use in different countries have resulted in a literature on intakes where studies are not comparable, thus limiting comparisons between countries and analysis of trends over time. Similarly, possibilities to compare intakes to recommendations and to establish links between intake and risk factors or disease end points are limited. ${ }^{7}$ The different

\footnotetext{
${ }^{1}$ Elsie Widdowson Laboratory, MRC Human Nutrition Research, Cambridge, UK; ${ }^{2}$ Baby Nutrition Division, Danone Research Centre for Specialised Nutrition, Wageningen, The Netherlands; ${ }^{3}$ Division of Human Nutrition, Wageningen University and Research Centre, Wageningen, The Netherlands; ${ }^{4}$ Nestlé Research Center, Lausanne, Switzerland; ${ }^{5}$ Coca-Cola Europe, SRA - Nutrition, Brussels, Belgium; ${ }^{6}$ MRC Childhood Nutrition Research Centre, University College London, London, UK; ${ }^{7}$ Department of Pediatrics, University of Verona, Verona, Italy; ${ }^{8}$ ILSI Europe a.i.s.b.l., Brussels, Belgium and ${ }^{9}$ Department of Biochemistry and Molecular Biology II, Centre for Biomedical Research, Institute of Nutrition and Food Technology, University of Granada, Granada, Spain. Correspondence: Dr C Matthys, ILSI Europe a.i.s.b.l., Avenue E. Mounier 83, Box 6, 1200 Brussels, Belgium. E-mail: publications@ilsieurope.be
}

Received 15 August 2011; revised 21 December 2011; accepted 22 December 2011; published online 4 April 2012 
Table 1. Overview of different terms used for sugars

\begin{tabular}{|c|c|c|}
\hline Total sugars & $\begin{array}{l}\text { All monosaccharides and disaccharides in a food, whether naturally occurring or added during processing } \\
\text { or cooking }\end{array}$ & 2,4 \\
\hline \multirow{2}{*}{ Added sugars } & $\begin{array}{l}\text { According to United States Economic Research Service: includes oligosaccharides derived from corn syrups } \\
\text { in its definition }\end{array}$ & 7 \\
\hline & $\begin{array}{l}\text { Others: all refined sugars (e.g., sucrose, maltose, lactose, glucose and dextrin) eaten separately at the table } \\
\text { or used as ingredients in processed foods }\end{array}$ & 6 \\
\hline Free sugars & $\begin{array}{l}\text { Recent: all monosaccharides and disaccharides added to foods by the manufacturer, cook and consumer, } \\
\text { plus sugars naturally present in honey, syrups and fruit juices }\end{array}$ & 39 \\
\hline Refined sugars & $\begin{array}{l}\text { Mainly European countries: sucrose, fructose, glucose, starch hydrolysates (glucose syrup, high-fructose corn } \\
\text { syrup) and other isolated sugar preparations such as food components used as such or added during food } \\
\text { preparation and manufacturing }\end{array}$ & 9 \\
\hline $\begin{array}{l}\text { Non-milk extrinsic } \\
\text { sugars (NMES) }\end{array}$ & $\begin{array}{l}\text { Total sugars minus: lactose in milk and milk products and sugars present within the cellular structures } \\
\text { of fruits and vegetables }\end{array}$ & 147 \\
\hline
\end{tabular}

Table 2. Classification of starch in the diet

\begin{tabular}{|c|c|c|}
\hline Type of starch & Examples & $\begin{array}{l}\text { Digestion in } \\
\text { small intestine }\end{array}$ \\
\hline $\begin{array}{l}\text { Rapidly digestible } \\
\text { starch (RDS) }\end{array}$ & $\begin{array}{l}\text { Freshly cooked } \\
\text { starchy foods }\end{array}$ & Rapid \\
\hline $\begin{array}{l}\text { Slowly digestible } \\
\text { starch (SDS) } \\
\text { Resistant starch (RS) }\end{array}$ & $\begin{array}{l}\text { Most raw } \\
\text { cereals, pasta }\end{array}$ & $\begin{array}{l}\text { Slow but } \\
\text { complete } \\
\text { Resistant }\end{array}$ \\
\hline
\end{tabular}

terms and their current definition or generally understood meaning are shown in Table 1.

\section{Starch}

Starch intake, if reported, is given only as a total. However, starch can be subdivided according to the rate and extent of its digestibility, as was first described by Englyst et al. ${ }^{11}$ in 1987. Resistant starch is not digested in the small intestine and therefore should not be considered under the label of digestible carbohydrates, but to date, this has not been separated out in any measurements of intakes of population groups. Table 2 shows the classification of starch in the diet.

\section{CARBOHYDRATE COMPOSITION OF INFANT FORMULAE AND COMPLEMENTARY FOODS}

The EU Directive 2006/141/EC of 22 December 2006 on infant formulae and follow-on formulae and amending Directive 1999/ 21/EC have established the compositional criteria of those products. Infant formulae when reconstituted as instructed by the manufacturer shall have a minimum of $9 \mathrm{~g}$ of total carbohydrates $/ 100 \mathrm{kcal}$ and a maximum of $14 \mathrm{~g} / 100 \mathrm{kcal}$. The following carbohydrates can be used: lactose, maltose, sucrose, glucose, maltodextrins, glucose syrup or dried glucose syrup, precooked starch and gelatinised starch, the two latter naturally free of gluten. The minimum content of lactose shall be $4.5 \mathrm{~g} / 100 \mathrm{kcal}$. If added, the sucrose shall not exceed $20 \%$ of the total carbohydrate content and the glucose shall not exceed $2 \mathrm{~g} / 100 \mathrm{kcal}$. The maximum authorised content of precooked starch and gelatinised starch is $2 \mathrm{~g} / 100 \mathrm{ml}$, and $30 \%$ of the total carbohydrate content. In follow-on formulae when reconstituted as instructed by the manufacturer, the minimum total carbohydrate shall be $9 \mathrm{~g} / 100 \mathrm{kcal}$, the maximum $14 \mathrm{~g} / 100 \mathrm{kcal}$ and the use of ingredients containing gluten is prohibited. The minimum content of lactose shall be $4.5 \mathrm{~g} / 100 \mathrm{kcal}$. Sucrose, fructose and honey can be used separately or as a whole but with a maximum of $20 \%$ of the total carbohydrate content.

The EU Directive 2006/125/EC of 5 December 2006 on processed cereal-based foods and baby foods for infants and young children has established the composition of products intended for infant weaning. For cereals, if sucrose, fructose, glucose, glucose syrups or honey are added to products mentioned, then the amount of added carbohydrates from these sources shall not exceed $7.5 \mathrm{~g} / 100 \mathrm{kcal}$ and the amount of added fructose shall not exceed $3.75 \mathrm{~g} / 100 \mathrm{kcal}$. If sucrose, fructose, glucose syrups or honey are added to baby foods, then the amount of added carbohydrate from these sources shall not exceed $5 \mathrm{~g} / 100 \mathrm{kcal}$ and the amount of added fructose shall not exceed $2.5 \mathrm{~g} / 100 \mathrm{kcal}$. In baby foods for infants and young children, the quantities of total carbohydrate shall not exceed $10 \mathrm{~g} / 100 \mathrm{ml}$ for vegetable juices and drinks based on them, $15 \mathrm{~g} / 100 \mathrm{ml}$ for fruit juices, nectars and drinks based on them, $20 \mathrm{~g} / 100 \mathrm{~g}$ for fruit-only dishes, $25 \mathrm{~g} / 100 \mathrm{~g}$ for desserts and puddings and $5 \mathrm{~g} / 100 \mathrm{~g}$ for other non-milk-based drinks.

\section{INTAKES, FOOD SOURCES, WEANING PRACTICES AND RECOMMENDATIONS}

Intakes

For the purpose of this review, a search was conducted of available information on dietary intakes of infants and children below the age of 4 years. A thorough search of the literature was conducted for studies or surveys conducted in the past 25 years, that is, since 1985 where an age group $<4$ years was included and where information about sugars and/or starch was given. Studies or surveys that only described total carbohydrate, with no further subdivision into sugars were not included. There was no limit to study size. Studies and surveys were found through PubMed searches under 'child' or 'infant' or 'toddler' or 'preschool' and 'intake' or 'diet' or 'dietary' or 'sugar' or 'sugars'. References in journal articles located in this manner were reviewed for secondary sources, although this was limited to 1985 onwards in an effort to report contemporary data only. Surveys known to the authors and published reports were also included. Only papers 
and reports in English were included. Data for studies were reported in different tables according to the manner in which sugars were described, namely total sugars (Table 3), added sugars (Table 4), NMES (Table 5), specific monosaccharides and disaccharides (sucrose (Table 6), fructose and/or lactose) and other definitions. In each table, results were subdivided into three age groups: 1 year and under, 1 year upwards and 2 years upwards. Where the age group reported extended beyond 4 years but the category was mainly $<4$ years, these were also included. Studies were tabulated in chronological order, and reported for males and females together. Details of the studies including the dietary assessment method used have also been included. Most studies used a complete method of assessment, such as a 24-h recall, or an estimated or weighed record.

Table 3 provides the results for studies that have reported 'total sugars' intake, meaning all monosaccharides and disaccharides in a food, whether naturally occurring or added during processing or cooking, as described in Table 1. For infants aged 1 year or less, energy intakes were generally in the range $700-900 \mathrm{kcal} /$ day, and varied with the precise age group of those included in the study. The proportion of carbohydrate was around 50\% energy. Values for total sugars tended to be similar among studies at around $30-35 \%$ energy. Starch intakes, for those few studies that report it, were $\sim 15-18 \%$ energy. These values can be explained by the major consumption in this age group being milk, either breast milk or formula, with little solid food until the second half of the first year of life. There are no obvious trends over time for the 30 years covered.

For studies reporting intakes for children aged 1 year and upwards, energy intakes ranged from 1000 to $1400 \mathrm{kcal} /$ day, with carbohydrate intakes of $120-180 \mathrm{~g} /$ day, representing $47-55 \%$ energy, partly varying with country. Fat intakes were lower in this age group compared with the younger infants. Total sugars ranged from $\sim 80$ to $115 \mathrm{~g} /$ day or $25-33 \%$ energy, very similar to the younger age group. Starch intakes, however, were somewhat higher than for the younger age group, since a greater proportion of solid food is consumed by this age group. There were no changes over time from the 1980s to more recent years.

A very similar picture was seen for studies reporting intakes of children aged 2 years upwards. Energy intakes were higher than those at younger ages, from $\sim 1200$ to $1500 \mathrm{kcal} /$ day. Carbohydrate intakes were $49-58 \%$ energy. The national study in Greece ${ }^{12}$ reported much lower carbohydrate and sugars intakes, and much higher fat ( $42 \%$ energy). This age group has yet slightly higher starch intakes for studies reporting this nutrient, representing $23 \%$ energy. There is no evidence of consistent changes over time.

Table 4 shows the five studies reporting 'added sugars' intake, as described by authors, irrespective of what this term included. Added sugars ranged from 4 to $13 \%$ energy. Total carbohydrate intakes were similar in these studies to those reporting 'total sugars'.

Table 5 shows the five studies reporting NMES intake, meaning total sugars minus lactose in milk and milk products and sugars present within the cellular structures of fruits and vegetables, as described in Table 1. NMES intake represented 11-19\% energy, with the lowest value for the youngest age group. In infants aged $<1$ year, NMES were also the lowest proportion of total sugars at $35 \%$, while in the children aged $>1$ year NMES ranged from 47 to $65 \%$. The proportion of NMES increases with age, so that by age 3-4 years, it is likely to be around $60 \%$ of total sugars or more.

Table 6 shows studies reporting sucrose intake. Sucrose intake ranged from 5 to $14 \%$ energy, with lower intakes in younger age groups. The only study on infants aged $<12$ months showed an intake of $5.9 \%$ energy. Because of the different ranges of age included in these studies, it is difficult to determine the reasons for the variability in the studies reporting from 1 year upwards, but those with wider age ranges tended to have higher values, suggesting that sucrose intakes increase with age, probably due to the increased variety of foods consumed.
A small number of studies have reported intakes of fructose. Studies from the United States and New Zealand indicate total fructose intakes ranging from 4 to $8 \%$ energy ${ }^{13-15}$ and increasing with age as the infant moves to a greater contribution from complementary feeding. Few differences have been seen over three decades in the United States where fructose intake is assessed in the NHANES (National Health and Nutrition Examination Survey), in spite of seemingly increased use of High Fructose Corn Syrup (HFCS) as sweetener in that country. ${ }^{14,16}$

Few studies of carbohydrate intake report the intake of lactose, in spite of its major contribution to the carbohydrate intake of infants. Breast milk contains $60-75 \mathrm{~g} / \mathrm{L}$ lactose, ${ }^{17,18}$ with variations from woman to woman. Final concentration is reached within a few days of birth, rising from just over $50 \mathrm{~g} / \mathrm{L}$ soon after birth. ${ }^{18}$ Mothers of premature infants have lower concentrations at birth, but these continue to rise for longer until they reach the term level. ${ }^{18}$ Lactose concentration remains constant throughout the months of lactation, ${ }^{17}$ and reductions in intake with age are a result solely of reduced milk intake. Total lactose intake has been reported in studies from Finland, ${ }^{19}$ the United States ${ }^{14}$ and New Zealand. ${ }^{15}$ According to the national data for the United States from 1988 to 1994, lactose intake decreased from 20\% energy for infants aged 2-11 months, to 7\% energy at 1-2 years of age and $5 \%$ at 3-5 years of age. For Finnish infants aged 13-23 months, lactose represented $23 \%$ energy, while for children aged 1-4 years from New Zealand, lactose intake was 14\% energy. These later figures are in line with the American data in terms of decreases with age.

\section{Food sources}

A small number of studies and surveys have reported the major food sources of carbohydrate and sugars in infants. The most comprehensive is that of a national survey of 488 British infants aged 6-12 months. ${ }^{20}$ This survey indicated that the major sources of carbohydrate in this age group were commercial infant foods $(24 \%)$, cereal products $(23 \%)$, milk and milk products $(17 \%)$ and infant formula (13\%). NMES provided $29 \%$ of total sugars intake for infants 6-9 months, and $41 \%$ for those 9-12 months, indicating that the majority of sugars intake in infants $<12$ months is intrinsic in foods, the greatest sources being milk and milk products and infant formula. The greatest contributors of NMES in this age group were juice and other beverages, with increasing contributions from sweet grain foods and confectionery.

According to the most recent UK NDNS (National Diet and Nutrition Survey), cereal and cereal products represent $40 \%$ of total carbohydrate intake of toddlers (1.5-3 years) in the United Kingdom. ${ }^{21}$ Within this age group, 'pasta, rice and miscellaneous cereals' and white bread were the largest contributors, both at $9 \%$ of total carbohydrate intake. Milk and milk products contributed $16 \%$, fruit $11 \%$ and vegetables and potatoes $10 \%$, with smaller contributions from beverages, $4 \%$ for fruit juice and 3\% from 'soft drinks, not low calorie'. In the previous National UK Survey in 1992-1993 in toddlers (1.5-2.5 years), several food groups contributed to carbohydrate intake in similar proportions as in the recent data, with cereal products the major contributor at $36 \%$, milk and milk products $16 \%$, and vegetables and potatoes $12 \%$. ${ }^{22}$ Fruit contribution was lower in the earlier survey ( $5 \%$ vs $11 \%)$ while that of beverages was higher (14\% vs $10 \%)$ with 'soft drinks, not low calorie' contributing to ( $11 \%$ vs $3 \%)$. According to the US FITS (Feeding Infants and Toddlers Study) of $2002^{\text {(ref. 23) }}$ for toddlers aged 12-24 months, milk, yogurt and 'ice cream, frozen yogurt and pudding' contributed $18 \%$ to carbohydrate intake, juice $12 \%$ and sweetened beverages $9 \%$. Grain products made a substantial contribution, at least $27 \%$ for the figures given for individual foods in this category.

In UK's recent data, the largest contributor to intake of NMES in toddlers $1.5-3$ years was beverages, at $31 \% .{ }^{21}$ Within beverages, 


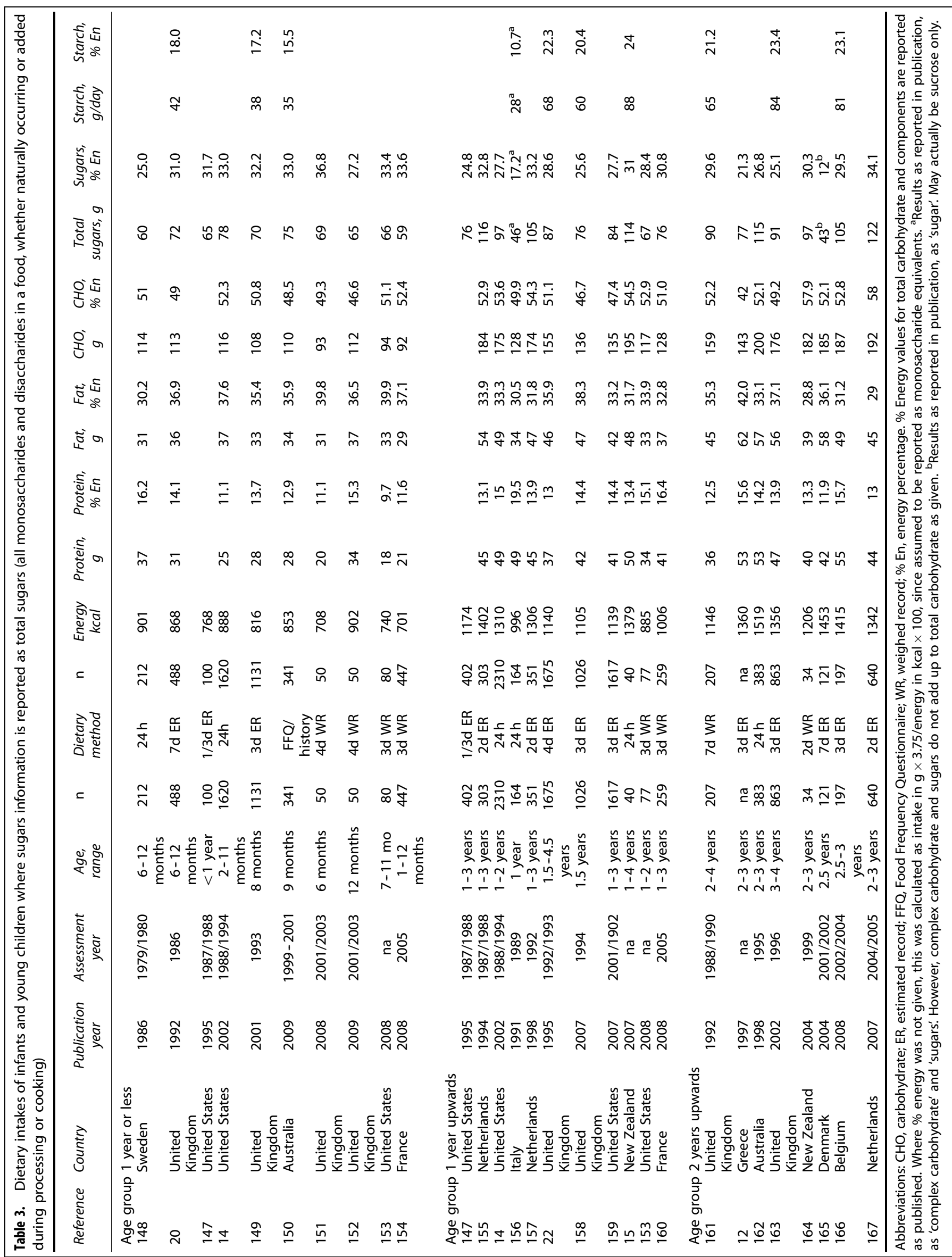




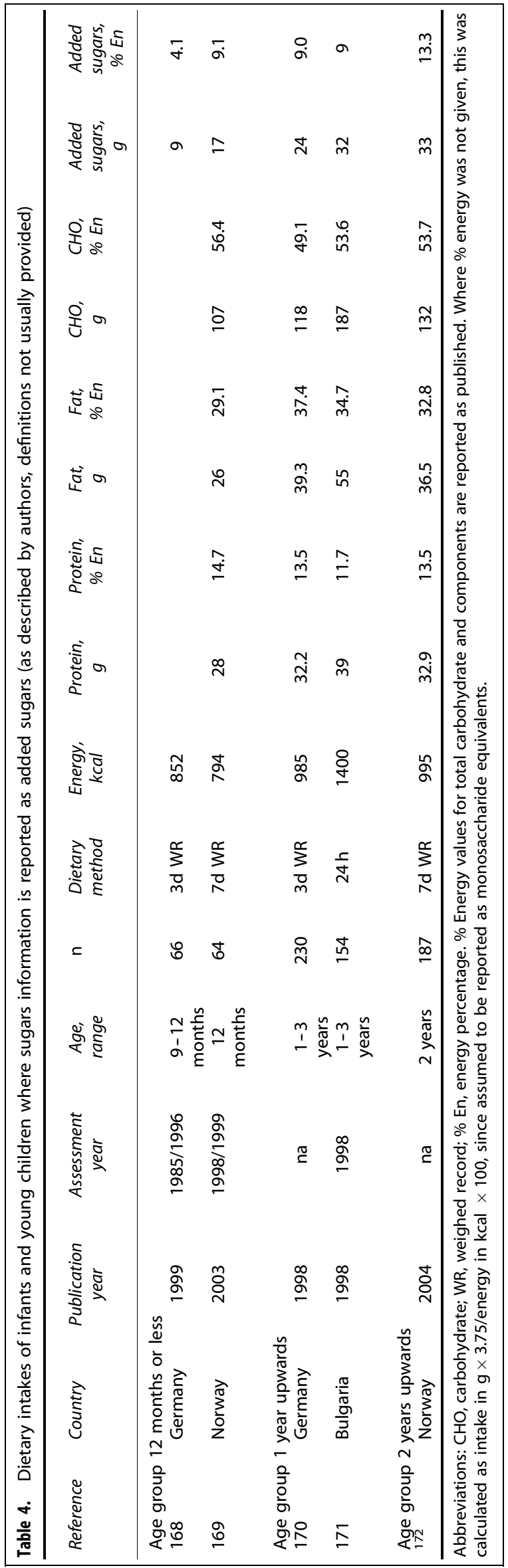

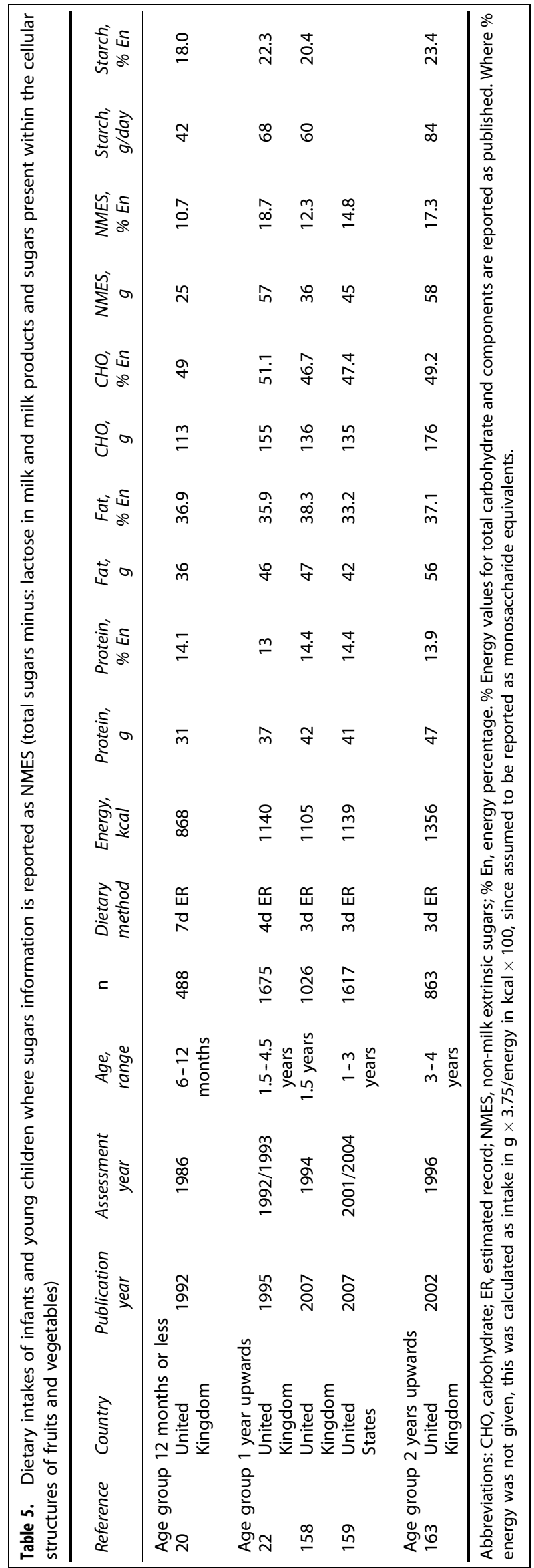




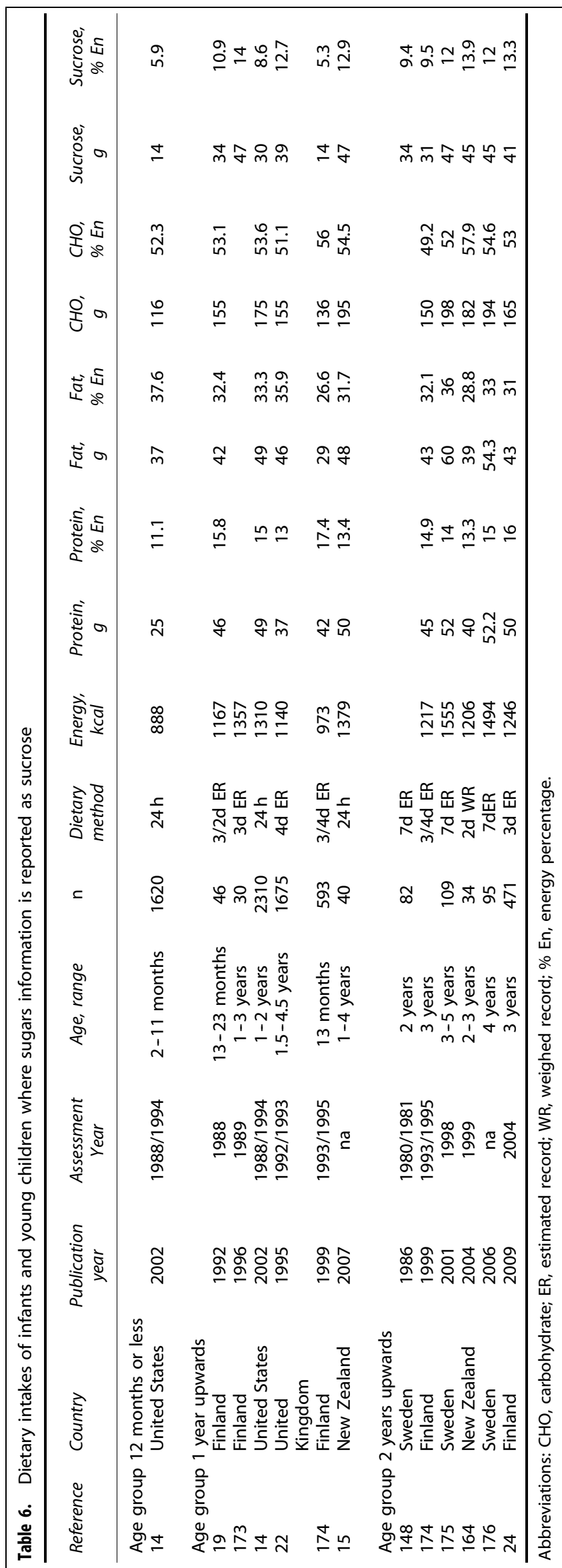

fruit juice contributed $17 \%$ and 'soft drinks, not low calorie' $12 \%$. Cereals and cereal products made a substantial contribution (23\%), as well as 'sugars, preserves and confectionery' (23\%) and milk and milk products (17\%). In the 1992/1993 survey, beverage contribution was $40 \%$ of NMES intake, within which fruit juice was $7 \%$ and 'soft drinks, not low calorie' $32 \%{ }^{22}$ The comparison of the two UK survey results for NMES confirms the findings seen with total carbohydrate on a reduction in contribution of 'soft drinks, not low calories' to carbohydrate intake. The contribution of cereals and cereal products at $21 \%$, and 'sugars, preserves and confectionery' at $25 \%$ did not change much since the previous survey. Milk and milk products contribution was lower (7\% vs $17 \%$ ) in the older survey, indicating an increase over time.

Of the very few other published reports of sources of specific monosaccharide and disaccharide intakes in infants and young children, a Finnish study has reported sources of added and naturally occurring sucrose in the diets of 3-year-old children. ${ }^{24}$ Juice drinks were by far the largest contributor to added sucrose (which was $85 \%$ of sucrose intake), at $27 \%$ of intake, with yogurt and cultured milks next at $13 \%$, chocolate and confectionery at $12 \%$ and sweet bakery at $11 \%$. For naturally occurring sucrose, fresh fruit and berries were the largest contributor at 38\%, with fruit and berry juice at $23 \% .{ }^{24}$ In the United States, where fructose is used more often as a sweetener than in Europe, Marriott et al. ${ }^{16}$ have reported sources of total, added and naturally occurring fructose intake from the 1998 to 2004 NHANES. For children aged $1-3$ years, added fructose represented $65 \%$ of all fructose intakes, somewhat lower than for older age groups. ${ }^{16}$ The contributors to added fructose of $1-3$ years were beverages (39\%), grain products $(26 \%)$, sugars and sweets (16\%) and milk and milk products (14\%). Naturally occurring fructose was largely from fruit and fruit products at $91 \%$ of intake. When expressed as a proportion of total fructose intake, fruit and fruit products were $38 \%$, beverages $25 \%$, sugars and sweets $10 \%$ and milk and milk products $9 \%$.

All these studies indicate the major contribution of beverages (for example, fruit juices, juice drinks or soft drinks) to the intake of 'added sugars' by young children, whether that be expressed as NMES, sucrose or fructose, depending on the measure used in the country reporting.

Timing of introduction of weaning food and type of food given There is very limited information on the role of eating behaviours such as eating frequency or portion sizes on the intake of carbohydrate or sugars in young children. However, there is literature on the timing of introduction of foods to infants and the type of foods that are introduced first. There is difficulty in interpreting these studies overall because of the changes in recommendations for timing of introduction of complementary feeding and the implementation of these recommendations in the different countries. Before 2001, the World Health Organisation $(\mathrm{WHO})^{25}$ global recommendation was that infants be exclusively breastfed for between 4 and 6 months before the introduction of complementary foods. The same year, Kramer and Kakuma ${ }^{26}$ published an analysis comparing exclusive breastfeeding for 6 months vs 3-4 months. The WHO commissioned an Expert Consultation to review this work, which led to the recommendation for exclusive breastfeeding for 6 months, with introduction of complementary foods and continued breastfeeding thereafter. ${ }^{27}$ This recommendation has been adopted widely by countries around the globe. In 2008, the ESPGHAN (European Society for Paediatric Gastroenterology and Nutrition) issued a position statement, focussing on healthy infants in Europe, stating that while exclusive breastfeeding for $\sim 6$ months is a desirable goal, all infants should start complementary feeding by 26 weeks (but not before 17 weeks). ${ }^{28}$ In this analysis of different developed countries, the timing of introduction and type of food given in infants therefore vary, both according to the recommendation in 
the surveyed country at the time of survey and the degree to which it has been taken up by the population.

According to a five EU countries study, solids were introduced in $6 \%$ of formula fed infants at the age of 3 completed months, in $37.2 \%$ at $4,96.2 \%$ at 6 , and $99.3 \%$ at 7 completed months, respectively. ${ }^{29}$ The median age of introduction was 19 weeks. Among the breastfed infants only $0.6 \%$ had received solids at the age of 3 completed months, whereas $17.3 \%, 87.1 \%$ and $97.7 \%$ received solids at the ages of 4,6 and 7 months, respectively, with a median age of introduction of 21 weeks. ${ }^{29}$ However, the type of foods and the main sources of carbohydrate have not yet been reported for this study.

The Euro-Growth study (11 participating countries) reported that fruit $(73 \%)$ and cereals (51\%) were the first foods given to most infants. ${ }^{30}$ In an Italian study, similar results were found, with $73 \%$ having fruit as the first solid food introduced and $64 \%$ having cereals. ${ }^{31}$ In the ABIS (All Babies in Southwest Sweden) study, data on over 10000 infants, the most common first foods were vegetables, specifically, potatoes, carrots and sweet corn or products containing these. ${ }^{32}$ Most of the infants in a Bavarian study received a mash of vegetable, meat and potato as their first solid food. ${ }^{33}$ In the Glasgow Longitudinal Infant Growth Study, commercially prepared cereals were the most commonly used first weaning foods, used by $82 \%$ of the mothers $(n=127)$, and these were subdivided into baby rice $(66 \%)$, baby cereal $(9 \%)$ and rusks $(5 \%) .{ }^{34}$ Only six infants $(5 \%)$ were given fruit or vegetable purees as their first weaning food. These studies show some differences between countries in terms of the type of first food introduced. However, these foods are generally high in carbohydrate and fibre, being dominated by fruit, cereals or vegetables.

Some investigations have been conducted on the contribution of meals and sizes of portions in relation to energy intake and obesity, but little literature could be found in relation to carbohydrate intake. Pearcey and de Castro $^{35}$ examined meal patterns and distribution of nutrients in 29 infants aged 9-16 months. They showed that in the morning (0600-1000 h), carbohydrate made a larger contribution to energy intake than in the afternoon (1100-1400 h) or evening (1700-2100 h), with the total intake of energy similar for these three time periods. ${ }^{35}$ The French nutrition survey conducted in 1999 reported intakes of specific foods by meal occasion for 3-14 year olds and showed that sugars containing foods such as baked goods and biscuits, as well as sugars themselves were consumed more at breakfast and snacks than at other meals, while fruit was consumed more at lunch than at any other meal. ${ }^{36}$ Beverages such as fruit juice and soft drinks were consumed fairly evenly over breakfast, lunch, dinner and snacks. It was not possible to separate this analysis further by age group and to examine young children only. According to the US FITS, ${ }^{37,38}$ beverages and foods typically consumed by infants and toddlers at morning snacks were water, cow's milk, crackers and pure fruit juice. Beverages frequently consumed at afternoon snacks were water, whole cow's milk, fruitflavoured drinks and pure apple juice. The most frequently consumed foods for an afternoon snack at home or day care were crackers or non-baby food cookies. Carbonated beverages consumption differed according to the consumption location: they were consumed at away lunches by $16 \%$ of toddlers, compared with $3 \%$ at home and none at day care. ${ }^{38}$ Overall, carbohydrate intake is greater at breakfast than at other meal occasions.

Current recommendations for the population and suggested recommendations for children

The Joint FAO/WHO Expert Consultation on Carbohydrates in Human Nutrition recommended an optimum diet of at least $55 \%$ of total energy from a variety of carbohydrate sources for all ages except for children under the age of 2 years as fat should not be specifically restricted below this age. ${ }^{10}$ The optimum diet should be gradually introduced beginning at 2 years of age. ${ }^{10}$ Both the 1997 FAO/WHO Expert Consultation ${ }^{10}$ and the 2002 WHO/FAO Expert Consultation ${ }^{39}$ recommended that total carbohydrate should provide $55-75 \%$ total energy, with $<10 \%$ total energy for free sugars. The FAO/WHO report of 2007 updated some of the key issues related to carbohydrates in human nutrition including terminology and classification, measurement, physiology and relationship to chronic diseases such as obesity, diabetes, cardiovascular disease and cancer. ${ }^{40}$ Based on these considerations, the European Food Safety Authority panel has recently proposed $45-60 \%$ energy as the reference intake range for carbohydrates and $<10 \%$ energy for sugars. ${ }^{41}$

There are scant data in infants and young children to establish adequate carbohydrate and sugars recommendations for these age groups. In infants, it could be proposed that the minimum carbohydrate intake should be close to that provided by human milk, that is, $40 \%$ of total energy, and lactose should be the main digestible carbohydrate. After the second semester and until 2 years of age, children should gradually increase the intake of digestible carbohydrates, for example, starch up to 55\%, although lactose should remain the major carbohydrate. Children of later ages should have a range of digestible carbohydrates similar to that recommended for adults. ${ }^{42}$ Although there is no official recommendation, based on the adult recommendations, it would be fair to recommend that intake of added sugars should be discouraged in infants. Indeed, longitudinal follow-up studies suggest that early flavour experiences and food preferences during infancy are likely to track into childhood and adolescence. ${ }^{43-45}$ Therefore, offering complementary foods without added sugars may be advisable not only for short-term health but also to set infant's threshold for sweet at lower levels later in life.

Since sucrose is the most cariogenic sugar, its consumption should be minimised in toddlers and preschool children. However, there is no scientific evidence to establish a specific dietary intake value for sucrose and other free sugars. Guidelines should include, avoiding frequent consumption of juice or other sugar-containing drinks in bottles or beakers, discouraging the habit of a child sleeping with a bottle, limiting cariogenic foods to mealtimes, and establishing good dental hygiene. ${ }^{41}$

\section{ABSORPTION OF CARBOHYDRATES IN INFANTS AND YOUNG CHILDREN}

In young infants, digestible carbohydrate is obtained from breast milk or formula largely in the form of lactose, which is broken down by lactase in the brush border of the small intestine to glucose and galactose, which are then absorbed via the Sodium/ Glucose Transporter. ${ }^{46}$ This transporter is expressed strongly from birth and its activity capacity is well able to cope with the amount of lactose consumed. ${ }^{47}$ Fructose, which is not present in breast milk but may be present in follow-on formula, or given as fruit juice early in life, is absorbed via the GLUT5 transporter. ${ }^{46,48}$ In animals, this transporter is known to be naturally low in abundance in early life, then increasing markedly and independently of diet before weaning. ${ }^{49}$ There is evidence that fructose transport is also delayed in humans. In young children, malabsorption following fructose ingestion was found to decrease from age 1 year to age 5 years. ${ }^{50}$ High intakes of fructose may therefore not be well tolerated in infants, with malabsorption leading to discomfort and diarrhoea. Evidence from animal studies indicates that increased intakes of fructose can stimulate expression of GLUT5, thus increasing fructose tolerance, ${ }^{49}$ which suggests that graded exposure in infancy, may overcome initial malabsorption. However, increased expression of GLUT5 remains to be demonstrated in humans.

Breast milk also contains carbohydrate in the form of oligosaccharides, which are not absorbed in the small intestine, 
and enter the large intestine, where they stimulate the growth on bacterial types such as bifidobacteria, resulting in potential beneficial effects on the colon and on immune responses and susceptibility to infection. As a result of growing research on the beneficial effects of oligosaccharides in breast milk, 'prebiotic' carbohydrates are now being added to some infant and toddler formulas. ${ }^{51}$ The effects of oligosaccharides on the health of infants and toddlers are currently an area of very active research, but are outside the scope of the current review that concentrates on those carbohydrates absorbed in the small intestine.

Starch is not present in breast milk, but can exist as partially hydrolysed components in infant formulas. ${ }^{52}$ Starch is digested through the actions of pancreatic $\alpha$-amylase and brush border glucoamylase and maltase. It has long been thought that the infant pancreas is able to synthesise $\alpha$-amylase, but that very little is secreted; ${ }^{53}$ however, newer research suggests that the pancreas cannot synthesise $\alpha$-amylase in the very young. ${ }^{54}$ Nevertheless, infant levels of mucosal glucoamylase are similar to those for adults and these are thought to be sufficient to deal with the starch content of the diet at that stage. ${ }^{52}$ At weaning, the infant is exposed to more complex forms of starch, and pancreatic $\alpha$ amylase is then required. It is known that in adults a proportion of starch consumed, termed as 'resistant starch', is not digested and absorbed in the small intestine. ${ }^{11,55}$ The extent of malabsorption of starch in infants has been little studied but recent work using ${ }^{13} \mathrm{C}$ starch incorporated into foodstuffs and then detected in breath, suggests that infants may not absorb on average $\sim 20 \%$ of the starch they consume, a somewhat greater proportion than in adults. ${ }^{56}$ The starch escaping absorption is fermented and like non-digested oligosaccharides, may have a number of benefits for the colon and overall health. The effects of starch escaping digestion and absorption are, like that of undigested oligosaccharides, outside the scope of the current review.

\section{ROLE OF CARBOHYDRATE IN DEVELOPMENT OF FOOD PREFERENCES, EFFECTS ON BEHAVIOURAL ASPECTS OF FOOD CHOICES}

Taste is an important determinant of food preferences, and food preferences are crucial in infants' and children's food choices. It is generally assumed that they eat what they like and refuse the food they dislike. ${ }^{57}$ There are two ways in which carbohydrate has an important role in the development of food preferences and, consequently, in food choice behaviour of infants and toddlers. One relates to our innate preference for sweet tastes and the other relates to our ability to learn food preferences based on the associations with the consequences of consumption (flavournutrient learning).

Human infants are born with an innate preference for sweet. Tasting a sweet solution elicits facial relaxation in the infant, with sucking and licking movements and an expression of enjoyment resembling a smile. ${ }^{58-61}$ This has been shown for sucrose concentrations ranging from 0.1 to $1 \mathrm{M}$. Furthermore, most infants and toddlers prefer a sweet solution over water. ${ }^{62-64}$ Infants can tolerate a painful stimulus, such as blood taking, with less distress if provided with a sweet solution to drink at the same time. ${ }^{65}$ It is thought that this innate preference for sweet has an evolutionary basis. A sweet taste in nature indicates energy, which is needed for optimal growth and development. ${ }^{43,66-68}$ Therefore, it would seem safe for the young to consume foods with a sweet taste. Breast milk is also sweet, ${ }^{62,69}$ and this would confirm the link between a sweet taste and safe energy.

Although a sweet taste is appreciated, there are individual variations in the extent of acceptance among infants ${ }^{60,64,70}$ and children. ${ }^{71}$ Schwartz et al. ${ }^{64}$ showed that although a sweet lactose solution was preferred over water, some infants rejected it. This inter-individual variation in sweet taste acceptance seems to increase during the first year of life. ${ }^{62-64}$
Two factors, genetics and sweet taste early experience, may account for these inter-individual variations. First, it is likely that genetic differences have a role. ${ }^{67,72,73}$ In one study, children who were most sensitive to bitter tastes preferred higher levels of sweetness in sucrose solutions, cereals and beverages. ${ }^{73}$ In contrast, other studies indicate that children and adults who are most sensitive to bitter tastes (the so-called tasters and super tasters) are often sweet dislikers. ${ }^{72,74}$ Second, experience with sweet foods and beverages may modulate children's sweetness preference and their consumption pattern. Children who were routinely fed sugar water during infancy had a higher consumption of sucrose solutions at 6 months of age ${ }^{62}$ and in their second year of life. ${ }^{63}$ In all, 6- to 10-year-old children who experienced sugar water during infancy preferred solutions with higher levels of sucrose compared with children who were rarely or minimally exposed to sugar water in infancy. ${ }^{71}$ Similarly, 4- to 7-year-old children whose mothers routinely added sugar to their children's foods were more likely to prefer apple juices with added sugar as well as cereals with higher sugar content. ${ }^{75}$

Because a sweet taste is highly liked, children can learn to like initially neutral or new foods by adding sweetness to these foods. This process is called flavour-flavour learning, as an association is established between a new or neutral food and the liked sweet taste resulting in an increased liking for that food. ${ }^{67,76-78}$

Besides the innate preference for sweetness, carbohydrate has an important role in the development of food preferences and behaviour. This is the process of flavour-nutrient learning, where an association is established between the flavour of a food and the pleasantly satiating effects of energy. Due to this principle, humans are predisposed to learn to like high-energy foods. ${ }^{66,67,76,77}$ Flavour-nutrient learning has been effectively used in children below the age of 5 years. ${ }^{79-81}$ In these studies, fruity flavours and new tastes such as orange chocolate, bubblegum and maple almond were associated with fat or carbohydrate in yoghurt drinks. Various studies indicate that flavour-nutrient learning influences children's food consumption patterns. Observations of food choices during lunchtime among 2-year-old children reveal that the children choose foods that are relatively high in energy. Meat and starchy products were mainly chosen, whereas vegetables-which are low in energy-were least chosen. ${ }^{82}$ Moreover, within the low-energy food category of fruit and vegetables, children prefer the fruits and vegetables that are more energy dense. ${ }^{83}$

Carbohydrate influences food preferences and food choices of infants and toddlers via our innate preference for sweet and our ability to learn to like foods that are relatively energy dense through the process of flavour-nutrient learning.

\section{ROLE OF CARBOHYDRATE ON COGNITION}

The idea that the brain might be sensitive both to the fluctuations in metabolism that occur in relation to nutrient intake and to longterm nutritional status remains relatively unexplored. The only area that has been much explored in relation to carbohydrate and the brain is that of sugars and cognition. Glucose has received particular attention because it is the preferred and primary source of energy for the brain, which requires a steady supply of around $100 \mathrm{mg} / \mathrm{min}$ of glucose in adulthood ${ }^{84}$ and approximately twice as much in childhood. ${ }^{85}$ The brain is energy greedy and particularly so in infancy when it consumes around $60 \%$ of dietary energy intake. The youngest children studied seem to have been 6-7 years. $^{86}$ Studies in these children suggest areas of cognition that might be influenced by glucose intake in younger age groups before the age of 3 . Overall, the studies report selective effects, that is, on some cognitive domains but not others, demonstrated by appropriate tests but overlooked if only tests of general ability are given. Most changes are seen in the domains of attention, selective aspects of memory and information processing. ${ }^{86,87}$ 
The brain appears to be sensitive to short-term variation in the availability of glucose ${ }^{88}$ and the degree of mental effort or cognitive demand involved in tasks is important in determining those susceptible to the effects of glucose. ${ }^{89}$

In one of the few areas where infants have been studied directly, the role of sugars in several aspects of behaviour was investigated. In one study, ${ }^{90}$ four different sugars (sucrose, glucose, fructose and lactose) were shown to differ in their ability to calm infants who were crying spontaneously. While sucrose and fructose proved equally effective calming agents, lactose was equivalent to water, a surprising result since lactose is the carbohydrate component of human milk. Although calming is not a cognitive outcome, brain and cognitive development may be enhanced in an infant who is calm and not suffering stress. This study also demonstrates that sugars may have distinctive effects and need to be investigated individually. Research has shown, for example, that memory for spoken words in very young infants is enhanced after a glucose feed ${ }^{91}$ but it is not yet known if different sugars have differential effects. Other studies investigated the role of sugars as reinforcers in early learning. Providing a sucrose solution while making eye contact with a researcher was shown to induce a face preference, an important component of infant behaviour, for that researcher. ${ }^{92}$ On the other hand, in very preterm infants, those $<31$ weeks gestational age, high repeated exposure to sucrose impaired motor development, alertness and orientation after 5 weeks, so caution and more research are required. ${ }^{93}$ Until we have a sound data base obtained from welldesigned studies we cannot determine the parameters of the effects of sugars on infant cognition.

\section{CONSEQUENCES FOR HEALTH OF SUGARS 'EXCESS'}

Nutrient dilution

Of the adverse consequences of excess sugars consumption suggested, one of the most frequently mentioned is an effect on the intake of other nutrients, particularly micronutrients, intake of which is said to be 'diluted' with increasing sugars consumption. There have been a number of investigations of nutrient intakes with increasing sugars intakes in young age groups, from various countries.

In the British NDNS of children 1.5-4.5 years, NMES intakes were divided into quintiles and related to intakes of energy and a number of key nutrients. ${ }^{94}$ No relationship between energy, iron, vitamin $D$ and NMES was seen. There were decreasing intakes of calcium, zinc, thiamin, riboflavin, niacin and folate with increasing NMES intakes. ${ }^{94}$ Vitamin C intakes increased with increasing NMES. Intakes of nutrients were compared with Dietary Reference Values, and only for zinc was the top quintile on NMES associated with mean intake below the Estimated Average Requirement for 1-4 years.

Erkkola et al. $^{24}$ investigated the effect of increasing intakes of added sucrose in Finnish children aged 3 years. Similarly to the British study, there was no association with energy intake. Higher sucrose intake was associated with lower intakes of most micronutrients, while no associations were seen with vitamin $A$, vitamin $C$ or copper.

Overby et al. ${ }^{95}$ examined nutrient dilution in 4-year-old Norwegian children. There were no differences in energy intake with increasing 'added sugar'. Again, no association with vitamin C intake was found. ${ }^{95}$

Similar results have been shown in surveys of older children ${ }^{96}$ and in studies such as the DONALD (Dortmund Nutritional and Anthropometric Longitudinally Designed) study, where the age range is wide $\left(2-18\right.$ years). ${ }^{6}$ While the measure of sugars varies from study to study, there are similarities in the results in terms of effects of increasing intake on other nutrients.

Overall intakes of most nutrients remain above recommended intake levels for all intakes of sugars, and it is generally admitted that it is difficult to determine sugars intakes above which intakes of other nutrients adversely compromise health. If there would be any concerns about the effects of sugars intakes on other nutrients, it would be only for the very highest levels of sugar intake.

\section{Hyperactivity}

Sugars have been implicated in hyperactivity, more recently described as 'attention deficit-hyperactivity disorder' since the 1970s, when Crook $^{97}$ observed that removal of sucrose from the diet resulted in improved behaviour, which was reversed by its reintroduction. Correlation studies also showed a relationship between sugar intake and destructive and aggressive behaviours. ${ }^{98}$ Many early studies had methodological problems, lacking a control group or double blind testing. ${ }^{85}$ More recent and better controlled studies have failed to find a relationship between sugar and activity, both in normal children and in those with attention deficit-hyperactivity disorder. In 1995, Wolraich et al. ${ }^{99}$ published a meta-analysis of 16 studies with good study designs and control, and concluded that sugar did not affect the behaviour of children. Of these, a small number were on very young children. Both Roshon and Hagen ${ }^{100}$ and Wolraich et al. ${ }^{101}$ studied children 3-5 years of age and found no differences between those given sugar and those given artificial sweetener in terms of behaviour and activity. ${ }^{100,101}$ Some believe that any relationships seen in the early studies may be the result of reverse causality-that is, more active children need more energy and therefore consume more sugar. ${ }^{102}$ It is also thought that parental perception of effects may have influenced results: In a study investigating parental expectations, different behaviours appeared when parents were told that their child had been given sugar, even though all parents were given placebo. ${ }^{103}$ In recent years, interest in sugar and behaviour and hyperactivity has waned.

\section{Overweight and obesity}

Excess body weight is the sixth most important risk factor contributing to the overall burden of disease worldwide and $\sim 110$ million of children are now classified as overweight or obese. ${ }^{104}$ The prevalence of overweight and obesity has increased dramatically in children in the past three decades in both developed and emerging developed countries and it is associated with a higher prevalence of cardiovascular and metabolic diseases, including type 2 diabetes, dyslipidemia, hypertension, atherosclerosis and non-alcoholic fatty liver disease later in life. ${ }^{105}$

The role of diet composition in weight control and obesity remains controversial. ${ }^{106}$ Unlike positive relationships being found for both fat and protein, ${ }^{28}$ investigations of dietary carbohydrate or of sugars do not suggest a positive relationship between intake of these and obesity. The number of studies in children is small, partly because of the small number of countries that have good sugars intake data, as indicated above. Where data do exist, the relationship between sugars and body mass index (BMI) is negative. Gibson analysed this relationship in the United Kingdom using the NDNS data. ${ }^{107}$ Most of these analyses are on adults or older children; those conducted on children demonstrate inverse associations between intake of either total carbohydrates or NMES and BMI, even when taking underreporting into account. The same result was found in New Zealand using national survey data obtained using a $24-h$ dietary recall. ${ }^{108}$ No relationship was found in Australia, using national survey data obtained in the same way as in New Zealand. ${ }^{109}$ In a large study in Norway, a negative association was found between added sugar and BMI in those 13 years old, but a positive relationship in those aged 4 years. This is one of the few studies on young children. ${ }^{95}$ Unfortunately, all these studies are cross-sectional; longitudinal analyses are clearly needed.

In recent years, there has been growing interest in the role of fructose in obesity and metabolic disease, particularly with the 
increased use of HFCS since the 1970s in the United States in particular and the concomitant increase in obesity over the same period. Some evidence has suggested a role for fructose and HFCS in obesity, through impacts on satiety, where fructose has been found in some studies to be less satiating than glucose or to have different effects on leptin and ghrelin. ${ }^{110-112}$ Effects on triglycerides and diabetes risk have also been shown by some investigators, but not by others. ${ }^{11,113-115}$ In the past few years, there have been workshops and Expert Panels reviewing the emerging literature in this new area, but to date, no compelling evidence for a specific effect of fructose on obesity or metabolic disease has been shown. ${ }^{16,117}$ Difficulties such as study design problems, dietary manipulation issues and intake levels above normal ranges confound conclusions. Moreover, the increase in HFCS use has not altered the ratio of fructose to glucose in the diet since ratios are similar to sucrose which was used as a sweetener before HFCS introduction. ${ }^{116}$ There is virtually no literature on physiological effects of fructose or HFCS on these types of outcomes in the very young age group that is the focus of this review and further work is needed for this age, as well as for the population in general, to clarify a specific role for fructose, if this exists.

Overall, the sparse literature suggests little evidence of a positive relationship between sugars in general or of any particular type in relation to body weight, with many studies showing an inverse relationship between the incidences of obesity with increased sugars intake. Clearly, more research is needed on younger children, since the studies reportedly have universally been of a cross-sectional design. However, most organisations recommend limiting sugar-containing foods for infants to reduce the likelihood of high consumption later in childhood and adolescence. ESPGHAN, for example, suggests that offering complementary foods without added sugars may be advisable for both short-term health and to set a lower threshold for sweet taste for later life. ${ }^{28}$

There is a substantial literature on the association between intake of soft drinks and body weight, with a number of studies on young children. Some of these investigations indicate that a greater consumption of sugar-sweetened beverages, including sugared fruit juices and drinks and carbonated beverages, is associated with weight gain and obesity, but such association has not been found in other studies. ${ }^{116,118-120}$ A retrospective cohort design was used to examine the association between sweet drink consumption and overweight at follow-up among 10904 children aged 2 and 3 years. ${ }^{121}$ Sweet drinks included vitamin C-containing juices, other juices, fruit drinks and sodas. Children who were at risk for overweight or were obese at baseline and consumed 1 to $<2$ drinks/day, 2 to $<3$ drinks/day and $\geqslant 3$ drinks/day had a significantly higher risk to become or remain overweight compared with the referent ( $<1$ drink/day). Increased beverage consumption (milk, 100\% fruit juice, fruit drinks and soda) was associated with an increase in the total energy intake of the children but not with their BMI. ${ }^{122}$ Among a longitudinal cohort of African-American preschool children, high consumption of sugar-sweetened beverages was significantly associated with an increased risk for obesity. ${ }^{123}$ In addition, children's familial predisposition to obesity may differentially affect their beverage consumption patterns and indeed the risk of overweight and obesity. ${ }^{124}$

Information on persistence of early sugar-sweetened beverage patterns throughout infancy and early childhood, and their influence on long-term dietary intake is very limited. ${ }^{125}$ In infancy and early childhood, many other factors such as lifestyle factors, including higher dietary intake and meal portion sizes and sedentarism, are significantly associated with obesity. However, overall, there is sufficient evidence for public health strategies to discourage overconsumption of sugary drinks as part of a healthy lifestyle. ${ }^{126}$ ESPGHAN suggests avoidance of frequent consumption of juice or other sugar-containing drinks in bottles or beakers, discouraging sleeping with a bottle and establishing good dental hygiene. ${ }^{28}$

Insulin resistance and diabetes

Quite different genetic, nutrition and environmental factors influence the development of type 1 insulin-dependent diabetes and type 2 non-insulin-dependent diabetes. However, no causal relationship has been reported for dietary carbohydrates and insulin-dependent diabetes.

Insulin resistance (IR) may be modulated by different environmental factors including dietary habits. However, there are scant data on how nutrients and other dietary components affect IR in children. The relationship between energy-dense food consumption and IR is based on observational studies. As yet it remains unclear whether this is an effect of the food per se or whether it is due to higher body weight and fat mass. ${ }^{127}$ The substantial reduction of overweight in children achieved by a highcarbohydrate and low-fat diet given during 1 year results in a significant decrease of IR, associated with an increase in plasma adiponectin and decreased levels of ghrelin and leptin. ${ }^{128}$ However, any successful body weight reduction can be expected to improve IR and this finding is not necessarily attributable to the high-carbohydrate content of the diet. ${ }^{127}$

There have also been a number of epidemiological studies that have examined the association between intake of dietary sugars and markers of IR. ${ }^{129}$ Several studies have shown an inverse relationship, others have found an opposite effect, while some further studies have revealed no association. The studies showing a positive association are for South Asian adults in the United Kingdom and for African-American children in the Unites States which could be explained by a genetic susceptibility to the detrimental effects of dietary sugars given the recognised high prevalence of diabetes in these ethnic groups; thus, it has been reported that both insulin clearance and insulin sensitivity inversely correlated with dietary fat/carbohydrate ratio in African-American children. ${ }^{130}$

Non-insulin-dependent diabetes is characterised by IR that is complicated by impaired insulin secretion at the time of appearance of hyperglycaemia and clinical diabetes. Although diet and nutrition are widely believed to have an important part in the development of non-insulin-dependent diabetes, specific dietary factors have not been clearly defined and much controversy remains about the relationship between the amount and types of dietary fat and carbohydrate and the risk of diabetes. ${ }^{131}$

High glycaemic responses to milks and foods can have negative health consequences for adults. ${ }^{132-134}$ Although there is little information on these effects in infants and young children, it can be expected that high glycaemic responses also have negative health consequences in this age group. Higher glycaemic responses are mainly due to the rate of digestion and absorption in the gastrointestinal tract. Different carbohydrates have different rates of digestion and corresponding glycaemic responses. ${ }^{135}$ Carbohydrates only consisting of glucose units initiate a higher glycaemic response than carbohydrates consisting of glucose with another monosaccharide unit. Additionally, carbohydrates with a shorter chain length have higher glycaemic responses than carbohydrates with longer chain lengths. ${ }^{136}$ Differences in rate of digestion are also known for different types of starch (with a slower rate of digestion of amylose when compared with amylopectin). ${ }^{137,138}$

\section{Dental caries}

The WHO World Oral Health Report of 2003 indicated that dental caries remain a major oral health problem in most industrialised countries, affecting $60-90 \%$ of school children and the majority of adults. According to the DMFT (Decayed, Missing and Filled Teeth) 
Index, the disease level is high in the Americas and several Asian countries, but relatively low in Africa.

It is anticipated that the incidence of dental caries will increase in many developing countries as a result of a growing consumption of sugars and inadequate exposure to fluoride. ${ }^{139}$ The report emphasises the recommendation of the WHO report on the Global Strategy on Diet, Physical Activity and Health that free (added) sugars should remain $<10 \%$ of energy intake and the consumption of foods/drinks containing free sugars should be limited to a maximum of four times per day, ${ }^{42}$ suggesting that this recommendation would benefit the incidence of oral disease as well as other chronic conditions. In a recent ILSI (International Life Sciences Institute) monograph on oral and dental disease, further detail of the connection between sugars and dental disease was given and the relationship between the two shown to depend on the timing of food consumption and the extent of fluoride exposure. ${ }^{140}$

Prevalence of caries-free children has been shown to be more associated with increased use of fluoride toothpaste than reductions in sugar intakes. Oral hygiene also has an important role. Hence, a specific sugar intake in one individual may have a different effect in another, depending on the local environment in the mouth, and affected by fluoride, oral hygiene and other foods eaten. ${ }^{140}$

The form of caries seen in young children is called ECC (Early Childhood (aries), a rampant form that can affect both the front teeth and molars. There are only a few investigations on the association between caries and sugar intake in this young age group. Karjalainen et al. ${ }^{141}$ conducted a prospective study of sucrose consumption on plaque and caries in participants of STRIP (Special Turku Coronary Risk Factor Intervention Project). They assessed diet and oral health in a subset of study participants at 3 years of age, and then again at 6 years. Daily sucrose intakes at 3 years of those who developed caries by 6 years were higher than those who were caries free, with no difference between the two groups for total carbohydrate. ${ }^{141}$

While there is strength in the Finnish study in that it is longitudinal, a difficulty is that intake of sucrose only was assessed, and other sugars, such as fructose, maltose and glucose are similarly cariogenic. ${ }^{140}$ Another major study in this age group is the British NDNS of preschool children aged 1.5-4.5 years, where sugars were measured as both total and NMES. It was concluded that NMES consumption was related to caries incidence, although this was influenced by frequency of brushing. ${ }^{142}$ However, Gibson and Williams carried out further analysis taking social class and tooth brushing into account and found that the only significant relationship between NMES and caries was in children from non-manual social class who brushed less than once a day. In those who brushed more often and in all children in manual class, there was no relationship between NMES and caries. Gibson $^{143}$ has also investigated sugars from breakfast cereals, and he found no relationship with caries.

Other studies in this age group have focussed on sugars containing foods, particularly beverages. About $13 \%$ of children in the NHANES III (1988-94) aged 2-10 years had a high carbonated soft drink consumption pattern and they also had a significantly higher dental caries experience in the primary dentition than did children with other fluid consumption patterns. A fluid intake pattern comprised mainly of milk, water or juice was less likely to be associated with dental caries. ${ }^{144}$ In the lowa Fluoride Study, beverage and nutrient intake patterns were obtained from 3-day food and beverage diaries completed at 1, 2, 3, 4 and 5 years of age; primary dentition was examined and weight and height measured at 4.5-6.9 years of age. ${ }^{145}$ Children with caries had lower family incomes, less educated parents, heavier mothers and higher soda-pop intakes at 2, 3 and 1-5 years than children without caries.

The relationship between sugars and dental caries is therefore complex. While sugars make some contribution to caries, this is confounded by socioeconomic status, frequency of food consumption and oral hygiene, particularly the use of fluoride containing toothpaste and frequency of brushing. It has been suggested that the sugar/caries relationship is sigmoid in nature, with western societies on the upper flattened area, implying that a large reduction in sugars intake would be required for a small change in caries incidence. ${ }^{146}$ Reducing frequency of consumption and improving oral hygiene may have a much more noticeable impact.

\section{CONCLUSION}

There are four major factors that limit the amount of comparable information about carbohydrate intakes in infants and young children. These are

(a) the limited number of studies performed in infants and young children worldwide;

(b) the differing approaches to the analysis of carbohydrate, giving different figures in food composition databases;

(c) the wide variety of terms used to describe intakes of sugar components in the diet:

(d) the dearth of information about starch intakes in the world, due in part to lack of interest in this nutrient, and in part to lack of information about starch content of foods in food composition databases in many countries.

In contrast to the large literature on breast and formula feeding, relatively little attention has been paid to the complementary feeding period, and there are a very limited number of studies for infants $<1$ year of age examining sources of carbohydrate, starch and sugars. There are also very few studies in toddlers.

Data suggest that sweet taste is preferred in early infancy and later food choices, but a clear association cannot be established yet.

It is no surprise, therefore, that the literature relating carbohydrate intake to the development of brain and to cognition is sparse and, for the age group under consideration here, almost non-existent.

Nutrient dilution consecutive to high-carbohydrate intakes seems to be a concern only for the very highest levels of intake.

In relation to obesity, there is no clear evidence that altering the proportion of total carbohydrate in the diet is an important determinant of energy intake and therefore BMI. Only a few studies have found a relationship between consumption of sugars or added sugars and obesity, with those positive studies limited to beverages and foods containing sugars. However, many other lifestyle factors, including the higher dietary intake, meal portion sizes and sedentarism, are significantly associated with obesity, therefore it would be wise for public health strategies to discourage overconsumption of sugary drinks as part of a healthy lifestyle.

Results are controversial on the relationship of intake of dietary sugars to IR, glucose intolerance and diabetes, and there is insufficient evidence on which to make recommendations in relation to digestible carbohydrate intakes. There is a lack of information on the different glycaemic responses of carbohydrates in children and their relationships with later life health have not been established.

In relation to dental caries, available data suggest a positive association with intake of added sugars, although this is also influenced by socioeconomic position and other lifestyle factors such as frequency of eating and use of fluoride toothpaste. An upper limit for intake of (added) sugars on the basis of a risk reduction for dental caries has not yet been established.

Future research needs

Much confusion remains in determining the optimal dietary carbohydrate composition for infants and toddlers. In the future, 
specific dietary recommendations in infancy and childhood might be best approached in an individualised manner, incorporating diet-gene interactions that are critical for understanding the relationships between diet and metabolic disease risk.

In the cognitive area, future studies should incorporate neurodevelopment tests as well as measuring overall cognitive level. Indications of which functions might be vulnerable can be obtained from studies with older children.

The influences of the intake of different type of carbohydrates on obesity and diabetes remain to be evaluated in prospective cohort studies covering infancy and childhood.

\section{CONFLICT OF INTEREST}

Dr Christophe Matthys is employed by ILSI Europe. Dr Stephen, Professor de Graaf, Dr Isaacs, Professor Maffeis and Professor Gil received an honorarium from ILSI Europe for their participation in this publication and/or reimbursement of their travel and accommodation costs for attending the related meetings.

\section{ACKNOWLEDGEMENTS}

All authors wrote, read and approved the final manuscript. AS and AG had primary responsibility for final content. This work was commissioned by the Nutrient Requirements Task Force of the European Branch of the International Life Sciences Institute (ILSI Europe). Industry members of this task force are Barilla G and R Fratelli, CocaCola Europe, Danone, DSM, Kellogg Europe, Nestle, Royal FrieslandCampina, Südzucker/BENEO Group, Ulker Bisküvi, Unilever. This publication was coordinated by Ms Evangelia Grammatikaki and Dr Christophe Matthys, scientific project managers at ILSI Europe. The ILSI Europe expert group on Role of Dietary Carbohydrates in the Diet of Infants and Toddlers would like to thank the past scientific project managers from ILSI Europe involved in this expert group: Ms Agnès Le Carré and Dr Stéphane Vidry. Further, the expert group would like to thank Ms Ria Dewit, Mr Sergi Migallon and Mr Frederic Timmermans for all the administrative support. For further information about ILSI Europe, please call + 3227710014 E-mail: info@ilsieurope.be or http://www.ilsi.eu. The opinions expressed herein are those of the authors and do not necessarily represent the views of ILSI Europe nor those of their companies.

\section{REFERENCES}

1 Stephen AM, Sieber GM, Gerster YA, Morgan DR. Intake of carbohydrate and its components--international comparisons, trends over time, and effects of changing to low-fat diets. Am J Clin Nutr 1995; 62, 851S-867S.

2 Paul AA, Southgate DA. McCance and Widdowson's 'The composition of foods': dietary fibre in egg, meat and fish dishes. J Hum Nutr 1979; 33, 335 - 336.

3 Department of Health. Dietary Sugars and Human Disease. HMSO: London, 1989 Report No. 37

4 Holland B, Welch AA, Unwin ID, Buss DH, Paul AA, Southgate DA. McCance and Widdowson's Composition of Foods. Her Majesty's Stationery Office: London, 1991.

5 Institute of Medicine of the National Academies. Reference Intakes for Energy, Carbohydrate, Fiber, Fat, Fatty Acids, Cholesterol, Proteins and Amino Acids. The National Academies Press: Washington, DC, 2002.

6 Alexy U, Sichert-Hellert W, Kersting M. Associations between intake of added sugars and intakes of nutrients and food groups in the diets of German children and adolescents. Br J Nutr 2003; 90, $441-447$.

7 Sigman-Grant M, Morita J. Defining and interpreting intakes of sugars. Am J Clin Nutr 2003; 78, 815S-826S

8 Bray GA, Nielsen SJ, Popkin BM. Consumption of high-fructose corn syrup in beverages may play a role in the epidemic of obesity. Am J Clin Nutr 2004; 79, 537- 543 .

9 The Nordic Council. Nordic Nutrition Recommendations 2004: Intergrating Nutrition and Physical Activity. The Nordic Food Policy Co-Operation Copenhagen, 2004.

10 Food Agriculture Organisation. Carbohydrates in human nutrition. Report of a Joint FAO/ WHO Expert Consultation. Food and Agriculture Organisation of the United Nations: Rome, 1998.

11 Englyst HN, Trowell H, Southgate DA, Cummings JH. Dietary fiber and resistant starch. Am J Clin Nutr 1987; 46, 873-874.

12 Roma-Giannikou E, Adamidis D, Gianniou M, Nikolara R, Matsaniotis N. Nutritional survey in Greek children: nutrient intake. Eur J Clin Nutr 1997; 51, 273-285.

13 Park YK, Yetley EA. Intakes and food sources of fructose in the United States. Am J Clin Nutr 1993; 58, 737S-747S.
14 Bialostosky K, Wright JD, Kennedy-Stephenson J, McDowell M, Johnson CL. Dietary intake of macronutrients, micronutrients, and other dietary constituents: United States 1988-94. Vital Health Stat 2002; 11, 1-158.

15 Metcalf PA, Scragg RK, Stewart AW, Scott AJ. Design effects associated with dietary nutrient intakes from a clustered design of 1 to 14 -year-old children. Eur $J$ Clin Nutr 2007; 61, 1064-1071.

16 Marriott BP, Cole N, Lee E. National estimates of dietary fructose intake increased from 1977 to 2004 in the United States. J Nutr 2009; 139, 1228S-1235S.

17 Mitoulas LR, Kent JC, Cox DB, Owens RA, Sherriff JL, Hartmann PE. Variation in fat, lactose and protein in human milk over $24 \mathrm{~h}$ and throughout the first year of lactation. Br J Nutr 2002; 88, 29-37.

18 Wojcik KY, Rechtman DJ, Lee ML, Montoya A, Medo ET. Macronutrient analysis of a nationwide sample of donor breast milk. J Am Diet Assoc 2009; 109, $137-140$.

19 Rasanen L, Ylonen K. Food consumption and nutrient intake of one- to two-yearold Finnish children. Acta Paediatr 1992; 81, 7-11.

20 Mills A, Tyler H. Food and Nutrient Intakes of British Infants Aged 6-12 Months. HMSO: London, 1992.

21 Bates B, Lennox A, Swan G. National diet and nutrition survey. Headline Results from Year 1 of the Rolling Programme (2008/2009). Food Standards Agency: London, 2009.

22 Gregory JR, Collins DL, Davies PSW, Hughes JM, Clarke PC. National Diet and Nutrition Survey: Children Aged 1.5 to 4.5 Years. HMSO: London, 1995 Report No. Volume 1.

23 Ziegler P, Briefel R, Clusen N, Devaney B. Feeding Infants and Toddlers Study (FITS): development of the FITS survey in comparison to other dietary survey methods. J Am Diet Assoc 2006; 106, S12-S27.

24 Erkkola M, Kronberg-Kippila C, Kyttala P, Lehtisalo J, Reinivuo H, Tapanainen $\mathrm{H}$ et al. Sucrose in the diet of 3-year-old Finnish children: sources, determinants and impact on food and nutrient intake. Br J Nutr 2009; 101, 1209-1217.

25 World Health Organisation. World Health Organisation's infant feeding recommendation. Weekly Epidemiological Record 1995; 70, 119-120.

26 Kramer MS, Kakuma R. The optimal duration of exclusive breastfeeding: a systematic review. Adv Exp Med Biol 2004; 554, 63-77.

27 World Health Organisation. The Optimal Duration of Exclusive Breastfeeding. WHO: Geneva, 2001.

28 Agostoni C, Decsi T, Fewtrell M, Goulet O, Kolacek S, Koletzko B et al. Complementary feeding: a commentary by the ESPGHAN Committee on Nutrition. J Pediatr Gastroenterol Nutr 2008; 46, 99-110.

29 Schiess S, Grote V, Scaglioni S, Luque V, Martin F, Stolarczyk A et al. Introduction of complementary feeding in 5 European countries. J Pediatr Gastroenterol Nutr 2010; 50, $92-98$.

30 Freeman V, van't Hof M, Haschke F. Patterns of milk and food intake in infants from birth to age 36 months: the Euro-growth study. J Pediatr Gastroenterol Nutr 2000; 31 (Suppl 1), S76-S85.

31 Giovannini M, Riva E, Banderali G, Scaglioni S, Veehof SH, Sala M et al. Feeding practices of infants through the first year of life in Italy. Acta Paediatr 2004; 93 $492-497$.

32 Brekke HK, Ludvigsson JF, van OJ, Ludvigsson J. Breastfeeding and introduction of solid foods in Swedish infants: the All Babies in Southeast Sweden study. Br J Nutr 2005; 94, 377-382.

33 Rebhan B, Kohlhuber M, Schwegler U, Koletzko BV, Fromme H. Infant feeding practices and associated factors through the first 9 months of life in Bavaria, Germany. J Pediatr Gastroenterol Nutr 2009; 49, 467-473.

34 Savage SA, Reilly JJ, Edwards CA, Durnin JV. Weaning practice in the Glasgow Longitudinal Infant Growth Study. Arch Dis Child 1998; 79, $153-156$

35 Pearcey SM, de Castro JM. Food intake and meal patterns of one year old infants. Appetite 1997; 29, $201-212$.

36 Agence Française de la Sécurité Sanitaire. Enquête individuelle et nationale sur les consommations alimentaires Enquête INCA 1999. Principaux Résultats. AFSSA: Maisons-Alfort, 2003.

37 Briefel R, Hanson C, Fox MK, Novak T, Ziegler P. Feeding Infants and Toddlers Study: do vitamin and mineral supplements contribute to nutrient adequacy or excess among US infants and toddlers? J Am Diet Assoc 2006; 106, S52-S65.

38 Ziegler P, Briefel R, Ponza M, Novak T, Hendricks K. Nutrient intakes and food patterns of toddlers' lunches and snacks: influence of location. J Am Diet Assoc 2006; 106, S124-S134

39 World Health Organisation. Diet, nutrition and the prevention of chronic diseases. Report of a Joint WHO/FAO Expert Consultation. World health Organisation: Geneva, 2003.

40 Nishida C, Martinez NF. FAO/WHO scientific update on carbohydrates in human nutrition: introduction. Eur J Clin Nutr 2007; 61 (Suppl 1), S1 - S4.

41 EFSA Panel on Dietetic Products, Nutrition and Allergies. Scientific opinion on dietary reference values for carbohydrates and dietary fibre. EFSA J 2010; 8 $14-62$. 
42 World Health Organisation. Global Strategy on Diet, Physical Activity and Health. WHO: Geneva, 2003.

43 Beauchamp GK, Mennella JA. Early flavor learning and its impact on later feeding behavior. J Pediatr Gastroenterol Nutr 2009; 48 (Suppl 1), S25-S30.

44 Skinner JD, Carruth BR, Wendy B, Ziegler PJ. Children's food preferences: a longitudinal analysis. J Am Diet Assoc 2002; 102, 1638-1647.

45 Larson NI, Neumark-Sztainer DR, Harnack LJ, Wall MM, Story MT, Eisenberg ME. Fruit and vegetable intake correlates during the transition to young adulthood. Am J Prev Med 2008; 35, 33 - 37

46 Boudry G, David ES, Douard V, Monteiro IM, Le Huerou-Luron I, Ferraris RP. Role of intestinal transporters in neonatal nutrition: carbohydrates, proteins, lipids, minerals, and vitamins. J Pediatr Gastroenterol Nutr 2010; 51, 380-401.

47 Ferraris RP. Dietary and developmental regulation of intestinal sugar transport. Biochem J 2001; 360, $265-276$

48 Corpe $\mathrm{CP}$, Burant $\mathrm{CF}$, Hoekstra JH. Intestinal fructose absorption: clinical and molecular aspects. J Pediatr Gastroenterol Nutr 1999; 28, 364-374.

49 Douard V, Ferraris RP. Regulation of the fructose transporter GLUT5 in health and disease. Am J Physiol Endocrinol Metab 2008; 295, E227-E237.

50 Nobigrot T, Chasalow FI, Lifshitz F. Carbohydrate absorption from one serving of fruit juice in young children: age and carbohydrate composition effects. J Am Coll Nutr 1997; 16, $152-158$.

51 Veereman-Wauters G. Application of prebiotics in infant foods. Br J Nutr 2005; 93 (Suppl 1), S57-S60.

52 Lee PC, Werlin S, Trost B, Struve M. Glucoamylase activity in infants and children: normal values and relationship to symptoms and histological findings. $J$ Pediatr Gastroenterol Nutr 2004; 39, 161 - 165.

53 Lebenthal E, Khin MU, Zheng BY, Lu RB, Lerner A. Small intestinal glucoamylase deficiency and starch malabsorption: a newly recognized alpha-glucosidase deficiency in children. J Pediatr 1994; 124, $541-546$.

54 Christian M, Edwards C, Weaver LT. Starch digestion in infancy. J Pediatr Gastroenterol Nutr 1999; 29, 116-124.

55 Stephen AM, Haddad AC, Phillips SF. Passage of carbohydrate into the colon Direct measurements in humans. Gastroenterology 1983; 85, 589-595.

56 Christian MT, Amarri S, Franchini F, Preston T, Morrison DJ, Dodson B et al. Modeling $13 \mathrm{C}$ breath curves to determine site and extent of starch digestion and fermentation in infants. J Pediatr Gastroenterol Nutr 2002; 34, 158 - 164.

57 Birch LL. Psychological influences on the childhood diet. J Nutr 1998; 128, 407S-410S.

58 Steiner JE. The gustofacial response: observation on normal and anencephalic newborn infants. Symp Oral Sens Percept 1973; 4, 254-278

59 Ganchrow JR, Steiner JE, Daher M. Neonatal facial expressions in response to different qualities and intensities of gustatory stimuli. Infant Behav Dev 1983; 6 , 189-200.

60 Rosenstein D, Oster H. Differential facial responses to four basic tastes in newborns. Child Dev 1988; 59, 1555 - 1568

61 Steiner JE, Glaser D, Hawilo ME, Berridge KC. Comparative expression of hedonic impact: affective reactions to taste by human infants and other primates. Neurosci Biobehav Rev 2001; 25, 53-74.

62 Beauchamp GK, Moran M. Dietary experience and sweet taste preference in human infants. Appetite 1982; 3, 139-152.

63 Beauchamp GK, Moran M. Acceptance of sweet and salty tastes in 2-year-old children. Appetite 1984; 5, 291 - 305.

64 Schwartz C, Issanchou S, Nicklaus S. Developmental changes in the acceptance of the five basic tastes in the first year of life. Br J Nutr 2009; 102, 1375-1385.

65 Eriksson M, Gradin M, Schollin J. Oral glucose and venepuncture reduce blood sampling pain in newborns. Early Hum Dev 1999; 55, $211-218$

66 Rozin P, Vollmecke TA. Food likes and dislikes. Annu Rev Nutr 1986; 6, 433-456.

67 Birch LL. Development of food preferences. Annu Rev Nutr 1999; 19, 41 - 62.

68 de Graaf C, Zandstra EH. Sweetness intensity and pleasantness in children, adolescents, and adults. Physiol Behav 1999; 67, 513-520.

69 Mennella JA. Taste and Smell. In: Swainan KF, Ashwall S (eds). Pediatric Neurology: Principles and Practice. CV Mosby Company: Philadelphia, 1999, pp 104- 113.

70 Cowart BJ. Development of taste perception in humans: sensitivity and preference throughout the life span. Psychol Bull 1981; 90, 43-73.

71 Pepino MY, Mennella JA. Factors contributing to individual differences in sucrose preference. Chem Senses 2005; 30 (Suppl 1), i319-i320.

72 Looy H, Weingarten HP. Facial expressions and genetic sensitivity to 6-npropylthiouracil predict hedonic response to sweet. Physiol Behav 1992; 52, $75-82$

73 Mennella JA, Pepino MY, Reed DR. Genetic and environmental determinants of bitter perception and sweet preferences. Pediatrics 2005; 115, e216-e222.

74 Yeomans MR, Tepper BJ, Rietzschel J, Prescott J. Human hedonic responses to sweetness: role of taste genetics and anatomy. Physiol Behav 2007; 91 264-273.
75 Liem DG, Mennella JA. Sweet and sour preferences during childhood: role of early experiences. Dev Psychobiol 2002; 41, 388-395.

76 Rozin P, Zellner D. The role of Pavlovian conditioning in the acquisition of food likes and dislikes. Ann NY Acad Sci 1985; 443, 189-202.

77 Eertmans A, Baeyens F, Van den Bergh O. Food likes and their relative importance in human eating behavior: review and preliminary suggestions for health promotion. Health Educ Res 2001; 16, $443-456$.

78 Havermans RC, Jansen A. Increasing children's liking of vegetables through flavour-flavour learning. Appetite 2007; 48, 259-262.

79 Birch LL, McPhee L, Steinberg L, Sullivan S. Conditioned flavor preferences in young children. Physiol Behav 1990; 47, $501-505$.

80 Johnson SL, McPhee L, Birch LL. Conditioned preferences: young children prefer flavors associated with high dietary fat. Physiol Behav 1991; 50, 1245-1251.

81 Kern DL, McPhee L, Fisher J, Johnson S, Birch LL. The postingestive consequences of fat condition preferences for flavors associated with high dietary fat. Physiol Behav 1993; 54, $71-76$.

82 Nicklaus S, Boggio V, Issanchou S. Food choices at lunch during the third year of life: high selection of animal and starchy foods but avoidance of vegetables. Acta Paediatr 2005; 94, 943-951.

83 Gibson EL, Wardle J. Energy density predicts preferences for fruit and vegetables in 4-year-old children. Appetite 2003; 41, $97-98$.

84 Messier C. Glucose improvement of memory: a review. Eur J Pharmacol 2004; 490, 33- 57.

85 Bellisle F. Effects of diet on behaviour and cognition in children. Br J Nutr 2004; 92 (Suppl 2), S227-S232.

86 Simmer K, Patole SK, Rao SC. Longchain polyunsaturated fatty acid supplementation in infants born at term. Cochrane Database Syst Rev 2008, CD000376.

87 Johnston CC, Filion F, Snider L, Majnemer A, Limperopoulos C, Walker CD et al. Routine sucrose analgesia during the first week of life in neonates younger than 31 weeks' postconceptional age. Pediatrics 2002; 110, $523-528$

88 Grantham-McGregor SM. Field studies in early nutrition and later achievement. Early Nutrition and Later Achievement ed. Academic Press: London, 1987.

89 Blass EM, Camp CA. The ontogeny of face recognition: eye contact and sweet taste induce face preference in 9- and 12-week-old human infants. Dev Psychol 2001; 37, 762-774.

90 Benton D, Brett V, Brain PF. Glucose improves attention and reaction to frustration in children. Biol Psychol 1987; 24, $95-100$.

91 Howlett J, Ashwell M. Glycemic response and health: summary of a workshop. Am J Clin Nutr 2008; 87, 212S-216S.

92 Chugani HT. A critical period of brain development: studies of cerebral glucose utilization with PET. Prev Med 1998; 27, 184-188.

93 Horne P, Barr RG, Valiante G, Zelazo PR, Young SN. Glucose enhances newborn memory for spoken words. Dev Psychobiol 2006; 48, 574- 582.

94 Gibson SA. Non-milk extrinsic sugars in the diets of pre-school children: association with intakes of micronutrients, energy, fat and NSP. Br J Nutr 1997; 78, 367-378.

95 Overby NC, Lillegaard IT, Johansson L, Andersen LF. High intake of added sugar among Norwegian children and adolescents. Public Health Nutr 2004; 7 , $285-293$.

96 Gibson S, Boyd A. Associations between added sugars and micronutrient intakes and status: further analysis of data from the National Diet and Nutrition Survey of Young People aged 4 to 18 years. Br J Nutr 2009; 101, $100-107$

97 Crook WG. Letter: an alternate method of managing the hyperactive child. Pediatrics 1974; 54, 656

98 Prinz RJ, Roberts WA, Hantman E. Dietary correlates of hyperactive behavior in children. J Consult Clin Psychol 1980; 48, 760 - 769.

99 Wolraich ML, Wilson DB, White JW. The effect of sugar on behavior or cognition in children. A meta-analysis. JAMA 1995; 274, 1617-1621.

100 Roshon MS, Hagen RL. Sugar consumption, locomotion, task orientation, and learning in preschool children. J Abnorm Child Psychol 1989; 17, 349-357.

101 Wolraich ML, Lindgren SD, Stumbo PJ, Stegink LD, Appelbaum MI, Kiritsy MC. Effects of diets high in sucrose or aspartame on the behavior and cognitive performance of children. $N$ Engl J Med 1994; 330, $301-307$.

102 Deheeger M, Rolland-Cachera MF, Fontvieille AM. Physical activity and body composition in 10 year old French children: linkages with nutritional intake? Int $J$ Obes Relat Metab Disord 1997; 21, 372 - 379.

103 Hoover DW, Milich R. Effects of sugar ingestion expectancies on mother-child interactions. J Abnorm Child Psychol 1994; 22, 501 - 515.

104 Haslam DW, James WP. Obesity. Lancet 2005; 366, 1197-1209.

105 Daniels SR, Jacobson MS, McCrindle BW, Eckel RH, Sanner BM. American heart association childhood obesity research summit report. Circulation 2009; 119, e489-e517.

106 Willett WC, Leibel RL. Dietary fat is not a major determinant of body fat. Am J Med 2002; 113 (Suppl 9B), 47S-59S. 
107 Gibson S, Neate D. Sugar intake, soft drink consumption and body weight among British children: further analysis of National Diet and Nutrition Survey data with adjustment for under-reporting and physical activity. Int J Food Sci Nutr 2007; 58, $445-460$

108 Parnell W, Wilson N, Alexander D, Wohlers M, Williden M, Mann J et al. Exploring the relationship between sugars and obesity. Public Health Nutr 2008; 11, $860-866$.

109 Cobiac L, Record S, Leppard P, Syrette J, Flight I. Sugars in the Australian diet results from the 1995 National Nutrition Survey. Nutr Diet 2003; 60, 152-173.

110 Teff KL, Elliott SS, Tschop M, Kieffer TJ, Rader D, Heiman M et al. Dietary fructose reduces circulating insulin and leptin, attenuates postprandial suppression of ghrelin, and increases triglycerides in women. J Clin Endocrinol Metab 2004; 89, 2963-2972.

111 Stanhope KL, Schwarz JM, Keim NL, Griffen SC, Bremer AA, Graham JL et al. Consuming fructose-sweetened, not glucose-sweetened, beverages increases visceral adiposity and lipids and decreases insulin sensitivity in overweight/ obese humans. J Clin Invest 2009; 119, 1322-1334.

112 Tappy L, Le KA. Metabolic effects of fructose and the worldwide increase in obesity. Physiol Rev 2010; 90, 23 - 46.

113 Livesey G, Taylor R. Fructose consumption and consequences for glycation, plasma triacylglycerol, and body weight: meta-analyses and meta-regression models of intervention studies. Am J Clin Nutr 2008; 88, 1419-1437.

114 Bantle JP. Dietary fructose and metabolic syndrome and diabetes. J Nutr 2009; 139, 1263S-1268S.

115 Schaefer EJ, Gleason JA, Dansinger ML. Dietary fructose and glucose differentially affect lipid and glucose homeostasis. J Nutr 2009; 139, 1257S-1262S.

116 Forshee RA, Storey ML, Allison DB, Glinsmann WH, Hein GL, Lineback DR et al. A critical examination of the evidence relating high fructose corn syrup and weight gain. Crit Rev Food Sci Nutr 2007; 47, $561-582$.

117 Murphy SP. The state of the science on dietary sweeteners containing fructose: summary and issues to be resolved. J Nutr 2009; 139, 1269S-1270S.

118 Gibson S. Sugar-sweetened soft drinks and obesity: a systematic review of the evidence from observational studies and interventions. Nutr Res Rev 2008; 21, $134-147$.

119 Mattes RD, Shikany JM, Kaiser KA, Allison DB. Nutritively sweetened beverage consumption and body weight: a systematic review and meta-analysis of randomized experiments. Obes $\operatorname{Rev} 2010 ; 12,346-365$

120 Vanselow MS, Pereira MA, Neumark-Sztainer D, Raatz SK. Adolescent beverage habits and changes in weight over time: findings from Project EAT. Am J Clin Nutr 2009; 90, 1489-1495.

121 Welsh JA, Cogswell ME, Rogers S, Rockett H, Mei Z, Grummer-Strawn LM. Overweight among low-income preschool children associated with the consumption of sweet drinks: Missouri, 1999-2002. Pediatrics 2005; 115, e223-e229.

122 O'Connor TM, Yang SJ, Nicklas TA. Beverage intake among preschool children and its effect on weight status. Pediatrics 2006; 118, e1010-e1018.

123 Lim S, Zoellner JM, Lee JM, Burt BA, Sandretto AM, Sohn W et al. Obesity and sugar-sweetened beverages in African-American preschool children: a longitudinal study. Obesity (Silver Spring) 2009; 17, $1262-1268$

124 Kral TV, Stunkard AJ, Berkowitz RI, Stallings VA, Moore RH, Faith MS. Beverage consumption patterns of children born at different risk of obesity. Obesity (Silver Spring) 2008; 16, $1802-1808$.

125 Fiorito LM, Marini M, Mitchell DC, Smiciklas-Wright H, Birch LL. Girls' early sweetened carbonated beverage intake predicts different patterns of beverage and nutrient intake across childhood and adolescence. J Am Diet Assoc 2010 110, $543-550$.

126 Malik VS, Schulze MB, Hu FB. Intake of sugar-sweetened beverages and weight gain: a systematic review. Am J Clin Nutr 2006; 84, 274-288.

127 Canete R, Gil-Campos M, Aguilera CM, Gil A. Development of insulin resistance and its relation to diet in the obese child. Eur J Nutr 2007; 46, $181-187$.

128 Reinehr T, Roth CL, Alexy U, Kersting M, Kiess W, Andler W. Ghrelin levels before and after reduction of overweight due to a low-fat high-carbohydrate diet in obese children and adolescents. Int J Obes (Lond) 2005; 29, 362-368.

129 Mann J, Cummings JH, Englyst HN, Key T, Liu S, Riccardi G et al. FAO/WHO scientific update on carbohydrates in human nutrition: conclusions. Eur J Clin Nutr 2007; 61 (Suppl 1), S132-S137.

130 Arslanian SA, Saad R, Lewy V, Danadian K, Janosky J. Hyperinsulinemia in AfricanAmerican children: decreased insulin clearance and increased insulin secretion and its relationship to insulin sensitivity. Diabetes 2002; 51, 3014-3019.

131 Hu FB, van Dam RM, Liu S. Diet and risk of Type II diabetes: the role of types of fat and carbohydrate. Diabetologia 2001; 44, 805-817.

132 Ludwig DS. The glycemic index: physiological mechanisms relating to obesity diabetes, and cardiovascular disease. JAMA 2002; 287, 2414-2423.

133 Brand-Miller JC. Glycemic load and chronic disease. Nutr Rev 2003; 61, S49-S55.
134 Aston LM. Glycaemic index and metabolic disease risk. Proc Nutr Soc 2006; 65 $125-134$.

135 Englyst HN, Hudson G. The classification and measurement of dietary carbohydrate. Food Chem 1996; 57, $15-21$.

136 Frost G, Dornhorst A. Glycemic index. In: Caballero B, Allen L, Prentice A (eds) Encyclopedia of Human Nutrition, 2nd edn. Elsevier: Oxford, 2006, pp 413-418.

137 Anderson GH, Woodend D. Effect of glycemic carbohydrates on short-term satiety and food intake. Nutr Rev 2003; 61, S17-S26.

138 Guyton A, Hall J. Fetal and Neonatal physiology. In: Guyton A, Hall J (eds) Textbook of Medical Physiology, 9th edn. W.B. Saunders Company: Philadelphia, 1996, pp $1047-1056$.

139 World Health Organisation. The World Oral Health Report. World Health Organisation: Geneva, 2003.

140 van Loveren C. Oral and dental health. Prevention of Dental Caries, Erosion, Gingivitis and Periodontitis. ILSI Europe: Brussels, 2009.

141 Karjalainen S, Soderling E, Sewon L, Lapinleimu H, Simell O. A prospective study on sucrose consumption, visible plaque and caries in children from 3 to 6 years of age. Community Dent Oral Epidemiol 2001; 29, 136-142.

142 Hinds K, Gregory JD. National Diet and Nutrition Survey: children aged 1.5 to 4.5 years, vol. 2. Report of the Dental Survey. HMSO: London, 1995.

143 Gibson SA. Breakfast cereal consumption in young children: associations with non-milk extrinsic sugars and caries experience: further analysis of data from the UK National Diet and Nutrition Survey of children aged 1.5-4.5 years. Public Health Nutr 2000; 3, 227-232.

144 Sohn W, Burt BA, Sowers MR. Carbonated soft drinks and dental caries in the primary dentition. J Dent Res 2006; 85, 262-266.

145 Marshall TA, Eichenberger Gilmore JM, Broffitt B, Stumbo PJ, Levy SM. Diet quality in young children is influenced by beverage consumption. J Am Coll Nutr 2005; 24, 65-75.

146 Gibson S, Williams S. Dental caries in pre-school children: associations with social class, toothbrushing habit and consumption of sugars and sugar-containing foods. Further analysis of data from the National Diet and Nutrition Survey of children aged 1.5-4.5 years. Caries Res 1999; 33, $101-113$.

147 Gibney M, Sigman-Grant M, Stanton Jr JL, Keast DR. Consumption of sugars. Am J Clin Nutr 1995; 62, 178S-193S.

148 Hagman U, Bruce A, Persson LA, Samuelson G, Sjolin S. Food habits and nutrient intake in childhood in relation to health and socio-economic conditions. A Swedish Multicentre Study 1980-81. Acta Paediatr Scand Suppl 1986; 328, 1 -56.

149 Noble S, Emmett P. Food and nutrient intake in a cohort of 8-month-old infants in the south-west of England in 1993. Eur J Clin Nutr 2001; 55, 698-707.

150 Conn JA, Davies MJ, Walker RB, Moore VM. Food and nutrient intakes of 9-month-old infants in Adelaide, Australia. Public Health Nutr 2009; 12, $2448-2456$.

151 Marriott LD, Robinson SM, Poole J, Borland SE, Godfrey KM, Law CM et al. What do babies eat? Evaluation of a food frequency questionnaire to assess the diets of infants aged 6 months. Public Health Nutr 2008; 11, $751-756$.

152 Marriott LD, Inskip HM, Borland SE, Godfrey KM, Law CM, Robinson SM. What do babies eat? Evaluation of a food frequency questionnaire to assess the diets of infants aged 12 months. Public Health Nutr 2009; 12, 967-972.

153 Fisher JO, Butte NF, Mendoza PM, Wilson TA, Hodges EA, Reidy KC et al. Overestimation of infant and toddler energy intake by 24-h recall compared with weighed food records. Am J Clin Nutr 2008; 88, 407-415.

154 Boggio V, Grossiord A, Guyon S, Fuchs F, Fantino M. Consommation alimentaire des nourrissons et des enfants en bas âge en France en 1997. Arch Pédiatr 1997; 6, $740-747$.

155 Lowik MR, Kistemaker C. Assessment of nutritional status in The Netherlands (Dutch Nutrition Surveillance System). Bibl Nutr Dieta 1994; 51, 68-73.

156 Bellu R, Ortisi MT, Incerti P, Mazzoleni V, Martinoli G, Agostoni C et al. Nutritional survey on a sample of one-year-old infants in Milan: intake of macronutrients. Nutr Res 1991; 11, 1221 - 1229

157 Lowik MR, Hulshof KFAM, van der Heijden LJM, Brussaard JH, Burema J, Kistemaker C et al. Changes in the diet in the Netherlands: 1987 - 88 to 1992. Int J Food Sci Nutr 1998; 49, S1-S64.

158 Cowin I, Emmett P. Diet in a group of 18-month-old children in South West England, and comparison with the results of a national survey. J Hum Nutr Diet 2007; 20, 254-267.

159 Marshall TA, Eichenberger-Gilmore JM, Larson MA, Warren JJ, Levy SM Comparison of the intakes of sugars by young children with and without dental caries experience. J Am Dent Assoc 2007; 138, 39-46.

160 Fantino M, Gourmet E. Apports nutritionnels en France en 2005 chez les enfants non allaités âgés de moins de 36 mois. Arch Pédiatr 2008; 15, 446- 455

161 Payne J, Belton N. Nutrient intake and growth in preschool children. I, Comparison of energy intake and sources of energy with growth. J Human Nutr Diet 1992; 5, 287-298. 
162 McLennan W, Podger A. National Nutrition Survey: nutrient intakes and physical measurements, Australia, 1995. Australian Bureau of Statistics: Canberra, 1998.

163 Emmett P, Rogers I, Symes C. Food and nutrient intakes of a population sample of 3-year-old children in the south west of England in 1996. Public Health Nutr 2002; 5, 55-64.

164 Grant AM, Ferguson EL, Toafa V, Henry TE, Guthrie BE. Dietary factors are not associated with high levels of obesity in New Zealand Pacific preschool children. J Nutr 2004; 134, 2561 - 2565.

165 Ulbak J, Lauritzen L, Hansen HS, Michaelsen KF. Diet and blood pressure in 2.5-y-old Danish children. Am J Clin Nutr 2004; 79, 1095 - 1102.

166 Huybrechts I, De Bacquer D, Cox B, Temme EH, Van Oyen H, De Backer G et al. Variation in energy and nutrient intakes among pre-school children: implications for study design. Eur J Public Health 2008; 18, 509-516.

167 Ocke M, van Rossum C, Fransen H, Buurma E, de Boer E, Brants $\mathrm{H}$ et al. Dutch National Food Consumption Survey Young Children 2005/2006. RIVM: Bilthoven, 2008 Report No.: RIVM rapport 350070001.

168 Alexy U, Kersting M, Sichert-Hellert W, Manz F, Schoch G. Macronutrient intake of 3- to 36-month-old German infants and children: results of the DONALD Study. Dortmund Nutritional and Anthropometric Longitudinally Designed Study. Ann Nutr Metab 1999; 43, 14-22.

169 Andersen LF, Lande B, Arsky GH, Trygg K. Validation of a semi-quantitative foodfrequency questionnaire used among 12-month-old Norwegian infants. Eur $J$ Clin Nutr 2003; 57, $881-888$.
170 Kersting M, Sichert-Hellert W, Alexy U, Manz F, Schoch G. Macronutrient intake of 1 to 18 year old German children and adolescents. Z Ernahrungswiss 1998; 37, $252-259$.

171 Petrova S. Dietary and Nutritional Status Survey of the Population in Bulgaria. National Center of Hygiene, Medical Ecology and Nutrition: Sofia, 1998.

172 Andersen LF, Lande B, Trygg K, Hay G. Validation of a semi-quantitative foodfrequency questionnaire used among 2-year-old Norwegian children. Public Health Nutr 2004; 7, 757-764.

173 Ylonen K, Virtanen SM, Ala-Venna E, Rasanen L. Composition of diet in relation to fat intake of children aged 1-7 years. J Hum Nutr Diet 1996; 9, 207-218.

174 Lagstrom H, Seppanen R, Jokinen E, Niinikoski H, Ronnemaa T, Viikari J et al. Influence of dietary fat on the nutrient intake and growth of children from 1 to 5 y of age: the Special Turku Coronary Risk Factor Intervention Project. Am J Clin Nutr 1999; 69, 516-523.

175 Sepp H, Lennernas M, Pettersson R, Abrahamsson L. Children's nutrient intake at preschool and at home. Acta Paediatr 2001; 90, 483-491.

176 Garemo M, Palsdottir V, Strandvik B. Metabolic markers in relation to nutrition and growth in healthy 4-y-old children in Sweden. Am J Clin Nutr 2006; 84, $1021-1026$.

(c) This work is licensed under the Creative Commons AttributionNonCommercial-No Derivative Works 3.0 Unported License. To view a copy of this license, visit http://creativecommons.org/licenses/by-nc-nd/3.0/

Supplementary Information accompanies the paper on European Journal of Clinical Nutrition website (http://www.nature.com/ejcn) 